\title{
Strengthening by Intermetallic Nanoprecipitation in Fe-Cr-Al-Ti alloy
}

C. Capdevila ${ }^{1 *}$, M.M. Aranda ${ }^{1}$, R. Rementeria ${ }^{1}$, J. Chao ${ }^{1}$, E. Urones-Garrote ${ }^{2}$, J. Aldazabal $^{3}$, M. K. Miller.

${ }^{1}$ MATERALIA Group, Centro Nacional de Investigaciones Metalúrgicas (CENIM-CSIC), Avda. Gregorio del Amo, 8, 28040 Madrid, Spain

2 Universidad Complutense de Madrid, Centro Nacional de Microscopía Electrónica (CNME), Av. Complutense s/n, E-28040, Madrid, Spain

${ }^{3}$ CEIT and Tecnun (University of Navarra), Paseo Manuel de Lardizábal 15, 20018 San Sebastián, Spain

${ }^{4}$ Oak Ridge National Laboratory, PO Box 2008, Oak Ridge, TN 37831-6139, USA

*corresponding author: ccm@cenim.csic.es

\section{Abstract}

The strengthening mechanism observed during ageing at temperatures of 435 and $475^{\circ} \mathrm{C}$ in the oxide dispersion strengthened (ODS) Fe-Cr-Al-Ti system has been investigated. Atom probe tomography (APT) and high-resolution transmission electron microscopy (HRTEM) analyses determined that the alloy undergoes simultaneous precipitation of $\mathrm{Cr}$-rich ( $\alpha^{\prime}$ phase) and nanoscale precipitation of TiAl-rich intermetallic particles ( $\beta^{\prime}$ phase). APT indicated that the composition of the intermetallic $\beta^{\prime}$ phase is $\mathrm{Fe}_{2} \mathrm{AlTi}_{0.6} \mathrm{Cr}_{0.4}$, and the evolving composition of $\alpha^{\prime}$ phase with ageing time was also determined. The results obtained from HRTEM analyses allow us to confirm that the $\beta^{\prime}$ precipitates exhibit a cubic structure and hence their crystallography is related to the Heusler-type $\mathrm{Fe}_{2} \mathrm{AITi}\left(\mathrm{L} 2_{1}\right)$ structure. The strengthening could be explained on the basis 
of two hardening effects that occur simultaneously: the first is due to the $\alpha-\alpha^{\prime}$ phase separation through the modulus effect, and the second mechanism is due to the interaction of nanoscale $\beta^{\prime}$ particles with dislocations.

Keywords: phase separation, ferrous alloy, mechanical alloying, atom probe tomography, thermoelectric power, spinodal decomposition.

\section{Introduction}

High-Cr ferritic steels are widely used for heat resistant structural applications in nuclear and thermal power plants and fast breeder reactors due to the favorable combination of properties, such as good swelling resistance, low coefficient of thermal expansion, high thermal conductivity, good oxidation and creep resistance, and high tensile/compressive strength at ambient and elevated temperature. However, the use of ferritic steel is limited to temperatures below $550{ }^{\circ} \mathrm{C}$ due to an inadequate creep strength above that limit. In order to overcome this limitation, oxide dispersion strengthened (ODS) ferritic steels have drawn much attention due to their excellent high-temperature tensile strength and creep resistance [1-4].

Besides the homogeneous dispersion of nano-sized oxides in the ferritic matrix, ODS ferritic steels usually exhibit high-strength and creep resistance properties as a consequence of being far from the equilibrium state $[5,6]$. Many features, such as a large proportion of interfaces and triple junctions, possible irregular distributions of alloying elements and admixtures, the occurrence of non-equilibrium phases and supersaturated solutions, residual stresses, and excess concentrations of lattice defects, increase the Gibbs free energy. All these features are closely connected with 
the non-equilibrium conditions of the ODS fabrication methods, such as powder technology $[7,8]$. Such conditions are prone to the formation of nanoscale precipitates that will significantly increase both the strength and creep resistance of the ODS ferritic steel.

In this paper, we study the simultaneous nanoscale precipitation processes that occur in an ODS ferritic steel during ageing at temperatures of 435 and $475{ }^{\circ} \mathrm{C}$, i.e., the $\alpha-\alpha^{\prime}$ phase separation and $\beta^{\prime}$ intermetallic precipitation. The goal is not only to explore the nature and mechanism of precipitation of TiAl-rich ( $\beta^{\prime}$-phase) particles, but to describe the interaction with the $\mathrm{Cr}$-rich $\alpha^{\prime}$-particles resulting from the $\alpha-\alpha^{\prime}$ phase separation, and the strengthening mechanisms induced by these nanoscale precipitation processes.

\section{Materials and Experimental Techniques}

PM 2000 TM is a yttria dispersion strengthened, mechanically alloyed, ferritic steel containing $\sim 20 \mathrm{Cr}$ and $5 \mathrm{Al}$ (wt. \% ) for oxidation and corrosion resistance. After mechanical alloying, the alloyed powder is canned, hot-extruded and hot-rolled into bar form [9-11]. The PM 2000 TM alloy used in this study was provided by PLANSEE $\mathrm{GmbH}$ in the form of as-rolled bars. The chemical composition of the commercial purity PM $2000^{\mathrm{TM}}$ used in this study as determined by X-ray Fluorescence is given in Table 1.

Table 1. Chemical composition of PM $2000^{\mathrm{TM}}$ as determined by X-ray Fluorescence

\begin{tabular}{|l|l|l|l|l|l|l|l|l|}
\hline & $\mathrm{Cr}$ & $\mathrm{Al}$ & $\mathrm{Ti}$ & $\mathrm{C}$ & $\mathrm{O}$ & $\mathrm{N}$ & $\mathrm{Y}$ & $\mathrm{Fe}$ \\
& & & & & & & & \\
\hline
\end{tabular}




\begin{tabular}{|l|l|l|l|l|l|l|l|l|}
\hline wt.-\% & 18.60 & 5.20 & 0.54 & 0.04 & 0.09 & 0.006 & 0.391 & balance \\
at.-\% & 18.50 & 10.10 & 0.58 & 0.17 & 0.28 & 0.022 & 0.228 & balance \\
\hline
\end{tabular}

The inspection of the microstructure was done using a combination of atom probe tomography (APT) and high-resolution transmission electron microscopy (HRTEM) imaging. TEM thin foils were prepared from cylindrical samples of $3 \mathrm{~mm}$ diameter which were cut along the rolling direction and they were mechanically thinned down to $0.05 \mathrm{~mm}$. Later, these discs were electropolished in a double jet Struers TenuPol-5, using a $5 \%$ perchloric acid, $15 \%$ glycerol and $80 \%$ ethanol mixture at $-6{ }^{\circ} \mathrm{C}$ and $20 \mathrm{~V}$. HRTEM examination was performed with a JEOL model JEM 3000F microscope, operating at $300 \mathrm{keV}$ and with a point-to-point resolution of $0.17 \mathrm{~nm}$.

In this study, two local-electrode atom probes (LEAP ${ }^{\oplus}$ ) (CAMECA instruments Inc. LEAP 2017 and 4000X HR) were used to quantify the size and composition parameters of the $\alpha-\alpha^{\prime}$ phase separation and $\beta^{\prime}$ precipitation. APT specimens were cut from bulk material and electropolished with the standard double layer and micropolishing methods [12]. For some specimens, focused ion beam (FIB) technique was used in the final stage of specimen preparation. The LEAP $^{\circledR}$ was operated in voltage pulse mode with a specimen temperature of $50 \mathrm{~K}$, a pulse repetition rate of $200 \mathrm{kHz}$, and a pulse fraction of $20 \%$. Only data sets with more than 2.5 million atoms were used to ensure that the reconstructed volume of material is sufficient to characterize the phase separation. 


\section{Results and discussion}

The relative increase in hardness, as compared with the as-hot rolled condition, during ageing treatments at 435 and $475{ }^{\circ} \mathrm{C}$ is shown in Fig. 1. An abrupt increase of $~ 75 \%$ was observed in the aged condition of $435{ }^{\circ} \mathrm{C}$ for times longer than $100 \mathrm{~h}$. However, the increase experienced at $475{ }^{\circ} \mathrm{C}$ is not as pronounced as the one observed in samples aged at $435^{\circ} \mathrm{C}$. The goal of this paper is to clarify the reason for this increment in the relative hardness.

\section{Nanoscale $\alpha$ - $\alpha$ phase separation}

It has been reported previously [13-15] that the $\alpha-\alpha^{\prime}$ phase separation process is the main hardening mechanism during ageing for temperature ranging between 400 and $515{ }^{\circ} \mathrm{C}$. The misfit effect between $\alpha$ and $\alpha^{\prime}$ phases and the incremental change of Young's modulus (modulus effect), as a consequence of the corresponding decrease in the lattice parameter during phase separation, are the main contributors to the hardening of PM $2000^{\mathrm{TM}}$ during aging [16].

Fig. 2 displays the isoconcentration surfaces obtained from APT analysis for the resulting microstructure after ageing at $435^{\circ} \mathrm{C}$ and $475^{\circ} \mathrm{C}$. The size and morphology of the $\mathrm{Cr}$ enriched $\alpha^{\prime}$ can be observed from these isosurfaces: For the long ageing time, the roughly spherical $\alpha^{\prime}$ particles are isolated and do not form a percolated microstructure. The morphology of these $\alpha^{\prime}$ particles is similar to the one previously observed in Fe-19 at.\% Cr binary alloys and distinctly different to the interconnected network structure observed in higher chromium content (24-45 at.\%) binary alloys [17]. At the low ageing temperatures of $435^{\circ} \mathrm{C}$, the morphology of the $\mathrm{Cr}$-enriched $\alpha^{\prime}$ 
phase is of a finer scale and keeps an interconnected network after much longer ageing times than that observed at $475^{\circ} \mathrm{C}$, as seen in Fig. 2 .

The composition of the $\alpha$ and $\alpha^{\prime}$ phases was evaluated with the use of proximity histograms [18]. These are profiles of local atomic concentrations vs. proximity to an isoconcentration surface whose composition is selected to represent an interphase. In this work 30 at.\% $\mathrm{Cr}$ isoconcentration surfaces were selected to systematically study the composition of the $\alpha$ and $\alpha^{\prime}$ phases. Table 2 summarizes the compositions of the $\alpha$ and $\alpha^{\prime}$ phases for samples aged at $435^{\circ} \mathrm{C}$ and $475^{\circ} \mathrm{C}$ during different times.

The chromium level in the center of $\alpha^{\prime}$ regions progressively increases with ageing time for both temperatures. The observation that the concentration of $\alpha^{\prime}$ phase is not constant indicates that phase separation cannot be described simply by classical nucleation and growth processes. Besides, previous work [15] reported a value of activation energy for $\alpha$ - $\alpha^{\prime}$ phase separation in PM $2000^{\mathrm{TM}}$ of $264 \mathrm{~kJ}^{\mathrm{mol}} \mathrm{m}^{-1}$ determined by means of thermoelectric power measurements. This value is close that of $248 \mathrm{~kJ}$. $\mathrm{mol}^{-1}$ for self-diffusion of $\mathrm{Cr}$ in $\alpha$-Fe [19], which is consistent with the assumption that $\alpha-\alpha^{\prime}$ phase separation is driven by $\mathrm{Cr}$-diffusion and the activation energy for nucleation, if any, should be small. 
Table 2. Compositions of the $\alpha$ and $\alpha^{\prime}$ phases for the different aging times and temperatures estimated from the APT proximity histogram following the procedure described in [18]. $\Delta \mathrm{C}_{\mathrm{cr}}$ stands for $\mathrm{Cr}$-compositional amplitude, and $\mathrm{k}_{\mathrm{Al}}$ for the Al partitioning coefficient between $\alpha^{\prime}$ and $\alpha$ phases.

\begin{tabular}{|c|c|c|c|c|c|c|c|c|c|}
\hline \multirow{2}{*}{$\stackrel{0}{\circ}$} & \multirow{2}{*}{ 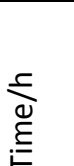 } & \multicolumn{3}{|c|}{$\alpha^{\prime}$ composition / at.\% } & \multicolumn{3}{|c|}{$\alpha$ composition / at.\% } & \multirow[t]{2}{*}{$\Delta \mathrm{C}_{\mathrm{Cr}}$} & \multirow[t]{2}{*}{$\mathrm{kAl}_{\mathrm{Al}}$} \\
\hline & & $\mathrm{Cr}_{\alpha^{\prime}}$ & $A l_{\alpha^{\prime}}$ & $\mathrm{Ti}_{\alpha^{\prime}}$ & $\mathrm{Cr}_{\alpha}$ & $\mathrm{Al}_{\alpha}$ & $\mathrm{Ti}_{\alpha}$ & & \\
\hline & 100 & $42.86 \pm 0.37$ & $10.29 \pm 0.23$ & $0.35 \pm 0.04$ & $14.17 \pm 0.51$ & $11.77 \pm 0.49$ & $0.50 \pm 0.10$ & $28.68 \pm 0.88$ & $1.14 \pm 0.07$ \\
\hline & 500 & $53.46 \pm 0.39$ & $7.67 \pm 0.22$ & $0.32 \pm 0.05$ & $15.55 \pm 0.16$ & $11.78 \pm 0.14$ & $0.57 \pm 0.03$ & $37.92 \pm 0.55$ & $1.53 \pm 0.06$ \\
\hline \multirow{3}{*}{$\stackrel{\sim}{\eta}$} & 1000 & $76.21 \pm 0.39$ & $4.59 \pm 0.40$ & $0.12 \pm 0.06$ & $15.10 \pm 0.14$ & $11.41 \pm 0.21$ & $0.50 \pm 0.05$ & $61.11 \pm 0.53$ & $2.48 \pm 0.26$ \\
\hline & 2016 & $82.68 \pm 0.51$ & $3.18 \pm 0.26$ & $0.15 \pm 0.06$ & $14.58 \pm 0.14$ & $11.90 \pm 0.13$ & $0.39 \pm 0.02$ & $68.36 \pm 0.45$ & $3.74 \pm 0.34$ \\
\hline & 3600 & $84.24 \pm 0.32$ & $3.06 \pm 0.16$ & $0.21 \pm 0.04$ & $15.88 \pm 0.12$ & $11.63 \pm 0.11$ & $0.65 \pm 0.03$ & $70.10 \pm 0.65$ & $3.79 \pm 0.23$ \\
\hline \multirow{5}{*}{ 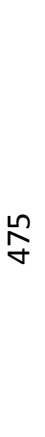 } & 100 & $27.43 \pm 0.19$ & $11.50 \pm 0.14$ & $0.78+0.04$ & $13.99 \pm 0.21$ & $11.43 \pm 0.20$ & $0.80 \pm 0.05$ & $13.44 \pm 0.40$ & $0.99 \pm 0.03$ \\
\hline & 500 & $46.14 \pm 0.37$ & $10.27 \pm 0.49$ & $0.80 \pm 0.14$ & $11.98 \pm 0.25$ & $11.33 \pm 0.25$ & $0.53 \pm 0.06$ & $34.16 \pm 1.05$ & $1.10 \pm 0.08$ \\
\hline & 1000 & $53.41 \pm 0.60$ & $8.76 \pm 0.35$ & $0.55 \pm 0.09$ & $10.88 \pm 0.15$ & $11.62 \pm 0.16$ & $0.41 \pm 0.03$ & $42.53 \pm 0.76$ & $1.33 \pm 0.07$ \\
\hline & 2040 & $62.12 \pm 1.05$ & $7.70 \pm 0.58$ & $0.63 \pm 0.18$ & $12.41 \pm 0.13$ & $11.27 \pm 0.13$ & $0.57 \pm 0.03$ & $49.70 \pm 1.18$ & $1.46 \pm 0.13$ \\
\hline & 3600 & $84.63 \pm 0.39$ & $2.98 \pm 0.19$ & $0.24 \pm 0.05$ & $16.17 \pm 0.12$ & $11.58 \pm 0.11$ & $0.69 \pm 0.03$ & $68.46 \pm 0.51$ & $3.89 \pm 0.28$ \\
\hline
\end{tabular}


It could be argued, at least to a first approximation, that the variations in the volume fraction, morphology, and size of $\alpha^{\prime}$ particles between the two ageing conditions, might be responsible for the increase in hardness shown in Fig. 1. Therefore, each of these parameters was examined.

A two-fold strategy was used to determine the volume fraction of the $\alpha^{\prime}$ phase. First, the volume fraction was calculated from the miscibility gap in the phase diagram. Secondly, an experimental determination was made from the lever rule of the APT data.

The positions of the miscibility gap and spinodal region in the Fe-Cr-Al-Ti system were established from the Computer Coupling of Phase Diagrams and Thermochemistry (CALPHAD) formulation with the commercial software MT-DATA thermodynamic database [20]. Following the method described elsewhere [19], the free energy of mixing $\left(\Delta G_{\text {mix }}\right)$ was determined. The variation of $\Delta G_{\text {mix }}$ with $\mathrm{Cr}$ content was evaluated for temperatures ranging between 300 and $700{ }^{\circ} \mathrm{C}$. The $\mathrm{Fe}-\mathrm{Cr}$ miscibility gap, as calculated by applying the common-tangent construction to the $\Delta \mathrm{G}_{\mathrm{mix}}$, is shown in Fig. 3a. The vertical dashed line in Fig. 3a corresponds to the chemical composition of the PM 2000 ${ }^{\mathrm{TM}}$ alloy. The evolution of $\mathrm{Cr}$ content of $\alpha^{\prime}$ phase for the different ageing times is also included in Fig. 3a. The $\mathrm{Cr}$ content of $\alpha^{\prime}$ phase matches the miscibility gap for 435 and $475{ }^{\circ} \mathrm{C}$ after ageing at $3600 \mathrm{~h}$. Therefore, it might be concluded that the $\alpha-\alpha$ ' phase separation is finished after this ageing time. 
The evolution of volume fraction of $\alpha^{\prime}$ phase with ageing time at 435 and $475{ }^{\circ} \mathrm{C}$ was calculated by the two different methods above mentioned. The former, named as "miscibility gap (MG)", is based on applying the conventional lever rule between the nominal alloy composition listed in Table $1, \alpha$-phase and $\alpha^{\prime}$-phase compositions measured by APT and listed in Table 2 (see Fig 3(a)).

The later method, named as "Lever rule (LR)", is based on the lever rule method described by Blavette et al. [21]. The nominal alloy concentration for each element minus the solute content in the $\alpha$ matrix is plotted against the difference in composition between $\alpha$ and $\alpha^{\prime}$ phases. The slope of the best-fit line passing through the origin for all elements gives the volume fraction of $\alpha^{\prime}$ phase. Figure 4 shows the LR diagrams for the two temperatures considered and the different ageing times indicating the volume fraction of $\alpha^{\prime}$ phase. Moreover, Fig. 4 also illustrates the partitioning trends of the solutes between $\alpha^{\prime}$ phase and the matrix ( $\alpha$ phase). For both ageing temperatures tested, $\mathrm{Cr}$ was the only element that partitioning into the $\alpha^{\prime}$ phase, whereas Fe and $\mathrm{Al}$ partitioned to $\alpha$-phase. The alignment of symbols ( $\mathrm{Fe}, \mathrm{Cr}, \mathrm{Al}$, Ti) shows the consistency of the APT data with the bulk composition as provided by the X-ray florescence data listed in Table 1.

The evolution phase fraction with ageing time, as determined by MG and LR methods is consistent for both ageing temperatures (see Fig 3(b)). Since the Cr-content of the $\alpha^{\prime}$ phase increases with ageing time as indicated in Fig. 3 (a), and there are only small changes in the $\mathrm{Cr}$ level of the $\alpha$ phase, the volume fraction of $\alpha^{\prime}$ decreases with ageing time. However, Fig. 3(b) indicates that the difference in volume fraction of $\alpha^{\prime}$ phase after ageing at 435 and $475^{\circ} \mathrm{C}$ is small for longer ageing times (>2000 h), and might 
not be responsible for the detected increase in hardness during ageing at $435{ }^{\circ} \mathrm{C}$. It might be possible that the difference in size of $\alpha^{\prime}$ particles is responsible for such behavior.

Although the size of the $\alpha^{\prime}$ regions can be roughly estimated from the isoconcentration surfaces shown in Fig. 2, a more robust statistical method, the autocorrelation function, was used [22]: the evolution of $\alpha^{\prime}$ size with ageing time may be estimated from the position of the first minima, $r_{\min }$, and the first maxima, $r_{1}$, and their variation with ageing time $[12,14]$. The position at which the autocorrelation function crosses zero, $r_{0}$, may also be used to estimate the size of the $\alpha^{\prime}$ regions. In these data, little significance should be placed on the autocorrelation function beyond the first maximum. For the analysis of experimental data, a shell thickness of $0.1 \mathrm{~nm}$ and a $r_{\max }$ $=100 \mathrm{~nm}$ were used. The results presented in Fig. 5 are the average of 10 autocorrelations centered at random positions within the volume of analysis. The parameters obtained from the autocorrelation function for the different ageing conditions are summarized in Table 3 . In both ageing conditions, the increase in the parameters indicates that the size of the $\alpha^{\prime}$ regions increases with ageing time. In the case of samples aged at $435{ }^{\circ} \mathrm{C}$, the autocorrelation function does not show any significant evidence of phase separation for ageing times shorter than $1000 \mathrm{~h}$. However, for the material aged at $475^{\circ} \mathrm{C}$, significant deviation from random behavior is observed after $100 \mathrm{~h}$. As the ageing time increases, the first minimum becomes more pronounced. It might be concluded from the results listed in Table 3 the differences in the scale of $\alpha^{\prime}$ phase between 435 and $475{ }^{\circ} \mathrm{C}$ at $1000 \mathrm{~h}$ of ageing cannot justify by 
themselves the significant differences in hardness shown in Fig. 1, since $r_{0}$ values at

both temperatures are quite similar.

Table 3. Size parameters estimated from the 3D radial autocorrelation function. $r_{0}$ is the position at which the autocorrelation function crosses zero, $r_{\min }$ is the position of the first minimum and $r_{1}$ is the position of the first maximum.

\begin{tabular}{|c|c|c|c|c|c|c|}
\hline & & $10 \mathrm{~h}$ & $100 \mathrm{~h}$ & $1000 \mathrm{~h}$ & $2040 \mathrm{~h}$ & $3600 \mathrm{~h}$ \\
\hline \multirow{3}{*}{$435^{\circ} \mathrm{C}$} & $r_{0}(\mathrm{~nm})$ & - & - & 3.0 & 3.5 & 6.5 \\
& $r_{\min }(\mathrm{nm})$ & - & - & 6.0 & 6.3 & 9.7 \\
& $r_{1}(\mathrm{~nm})$ & - & - & 12.4 & 13.8 & 20.8 \\
\hline \multirow{3}{*}{$475^{\circ} \mathrm{C}$} & $r_{0}(\mathrm{~nm})$ & - & 4 & 3.9 & 6 & 9 \\
& $r_{\min }(\mathrm{nm})$ & 1.5 & 4.3 & 6.7 & 7 & 14 \\
& $r_{1}(\mathrm{~nm})$ & 2 & 9 & 10.1 & 14 & 34 \\
\hline
\end{tabular}

\section{Mechanism for nanoscale $\alpha^{\prime}$ precipitation}

The temporal evolution of the concentration of the $\alpha^{\prime}$ phase shown in table 2 reveals that a non-classical nucleation regime occurs in this alloy at both ageing temperatures studied. It is well known that the theoretical description of classical nucleation requires the nucleus composition to be uniform and almost equal to the equilibrium composition of the precipitating phase. However, it is observed in table 2 that the composition of the $\alpha^{\prime}$ particles changes with increasing time and during early stages recorded it is well below the equilibrium composition. During the $\alpha^{\prime}$ precipitation process the $\mathrm{Cr}$ diffusion is the rate-limiting step [15]. This behavior is characteristic of a coarsening regime, the volume fraction not altering the time exponent predicted by the Lifshitz, Slyozov and Wagner (LSW) theory [23-25]. This theory predicts the power law coarsening of the mean precipitate size $R(t)$ varying as $\sim t^{1 / 3}$. The coarsening exponent of $1 / 3$ is a limiting value since LSW theory only takes into account long range 
diffusion. This is consistent with the evolution of the size of the $\alpha^{\prime}$ phase regions reported in Table 3. The experimental data obtained from the autocorrelation function analyses at each temperature were fitted to a power law and the time exponent was estimated. A time exponent of $0.33\left(R^{2}=0.92\right)$ was obtained from the measurements of the first minimum, and a corresponding value of $0.37\left(R^{2}=0.81\right)$ for the measurements of the first maximum. In LSW theory, the growth rate of particle diameters slows as decomposition proceeds, and the distance between the remaining particles gradually increases. Those results, along with the results for compositional evolution of $\alpha^{\prime}$ particles reported in Table 2, allow us to conclude that the system is in a coarsening regime.

The $\mathrm{Cr}$ enrichment in $\alpha^{\prime}$ particles together with no evidence of further nucleation events as phase separation proceeds, might explain the decrease in volume fraction obs-erved with ageing time (see Fig. 3(b)). Although the initial supersaturation is high enough, the formation of $\alpha^{\prime}$ particles would lead to a reduction in solute in the $\alpha$ matrix leading to an increase of the stable particle critical size [26]. Consequently, all particles with a size under this critical value will dissolve. Then, coarsening of large particles and dissolution of small particles lead to a reduction in number density. Since the reduction of solute in the matrix is significant after $100 \mathrm{~h}$, e.g., the $\mathrm{Cr}$ concentration in the $\alpha$ phase after $100 \mathrm{~h}$ at $435{ }^{\circ} \mathrm{C}$ is 14.17 at. \% (see Table 2), below the nominal value of 18.5 at. \% reported in Table 1 , the possibility for further formation of $\alpha^{\prime}$ is impeded. This is consistent with the observed reduction in volume fraction of $\alpha^{\prime}$ phase observed with ageing time as shown in Fig. 3(b). 


\section{The nanoscale $\beta^{\prime}$ phase}

The detailed APT characterization of the microstructure revealed the existence of a second precipitate that was enriched in $\mathrm{Ti}$ and $\mathrm{Al}$, as shown in the atom maps after ageing for $3600 \mathrm{~h}$ at $435{ }^{\circ} \mathrm{C}$ and at $475{ }^{\circ} \mathrm{C}$ (Figures 6(a) and Fig. $6(\mathrm{~b})$ respectively). Figure 6(c) shows the volume fraction of $\beta^{\prime}$ phase for the material aged for $2016 \mathrm{~h}$ at $435{ }^{\circ} \mathrm{C}$ (value of $\sim 1 \%$ ) determined from the LR-method described in previous sections. The $\beta^{\prime}$ phase was present in a significantly lower number density compared to the $\alpha^{\prime}$ phase. Note that the location of the atom maps and concentration profiles shown in Figs. 6(a) and 6(b) were selected to also show a $\sim 10 \mathrm{~nm}$ diameter, spheroidal Al- and Ti- enriched $\beta^{\prime}$ phase (and are not representative of the relative volume fractions of the phases). An interesting observation is the common interface between the $\alpha^{\prime}$ and $\beta^{\prime}$ phases. The co-development and morphology of the $\alpha^{\prime}$ and $\beta^{\prime}$ phases will be described in detail in subsequent paragraphs.

A 2 at.\% Ti isoconcentration surface was selected to determine the composition of the $\beta^{\prime}$ phase from the analysis of proximity histograms. Proximity histograms for $\mathrm{Cr}, \mathrm{Al}$ and Ti for samples aged at $435{ }^{\circ} \mathrm{C}$ for 500,1000 and $2016 \mathrm{~h}$ were analyzed across the $\alpha / \beta^{\prime}$ interphase to estimate the composition for the $\beta^{\prime}$ phase. The resulting compositions of the $\alpha$ and $\beta^{\prime}$ phases are summarized in Table 4 . These results reveal that the $\mathrm{Al}$ and $\mathrm{Ti}$ contents increase for ageing times lower than $2000 \mathrm{~h}$, and then attain a constant value. Conversely, $\mathrm{Cr}$ is depleted from the $\beta^{\prime}$ particles and appears to be incorporated into the $\alpha^{\prime}$ phase rather than the $\alpha$ matrix. The equilibrium composition of the $\beta^{\prime}$ phase appears to be attained after ageing for $2016 \mathrm{~h}$. Finally, the equilibrium composition of the $\beta^{\prime}$ particle is listed in Table 5. 
Table 4. Compositions of the $\alpha$ and $\beta^{\prime}$ phases for different aging times at $435^{\circ} \mathrm{C}$ as estimated from the proximity histograms. $\Delta \mathrm{C}_{\mathrm{Ti}}$ stands for Ti-compositional amplitude, and $\mathrm{k}_{\mathrm{Ti}}$ for the $\mathrm{Ti}$ partitioning coefficient between $\beta^{\prime}$ and $\alpha$ phases.

\begin{tabular}{|c|c|c|c|c|c|c|c|c|}
\hline \multirow{2}{*}{ 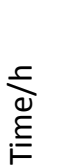 } & \multicolumn{3}{|c|}{$\beta^{\prime}$ composition / at.\% } & \multicolumn{3}{|c|}{$\alpha$ composition / at.\% } & \multirow[t]{2}{*}{$\Delta \mathrm{C}_{\mathrm{Ti}}$} & \multirow[t]{2}{*}{$\mathrm{K}_{\mathrm{Ti}}$} \\
\hline & $\mathrm{Cr}_{\beta^{\prime}}$ & $A l_{\beta^{\prime}}$ & $\mathrm{Ti}_{\beta^{\prime}}$ & $\mathrm{Cr}_{\alpha}$ & $\mathrm{Al}_{\alpha}$ & $\mathrm{Ti}_{\alpha}$ & & \\
\hline 100 & $20.77 \pm 0.46$ & $14.04 \pm 0.39$ & $2.27 \pm 0.18$ & $19.72 \pm 1.66$ & $12.07 \pm 1.36$ & $0.27 \pm 0.22$ & $2.00 \pm 0.40$ & $8.54 \pm 7.64$ \\
\hline 500 & $21.24 \pm 1.59$ & $18.71 \pm 1.57$ & $7.83 \pm 1.09$ & $|18.39 \pm 0.37|$ & $11.65 \pm 0.30$ & $0.18 \pm 0.04$ & $7.66 \pm 1.13$ & $43.75 \pm 15.79$ \\
\hline 1000 & $16.57 \pm 1.19$ & $22.35 \pm 1.33$ & $11.58 \pm 1.02$ & $19.72 \pm 1.66$ & $12.07 \pm 1.36$ & $0.27 \pm 0.22$ & $11.42 \pm 1.05$ & $44.13 \pm 20.99$ \\
\hline 2016 & $11.97 \pm 1.30$ & $24.50 \pm 1.77$ & $14.58 \pm 1.48$ & $17.53 \pm 0.38$ & $12.86 \pm 0.33$ & $0.36 \pm 0.06$ & $14.22 \pm 1.54$ & $40.89 \pm 10.93$ \\
\hline 3600 & $11.05 \pm 1.20$ & $24.80 \pm 1.30$ & $14.88 \pm 1.40$ & $17.35 \pm 0.80$ & $12.80 \pm 1.30$ & $0.35 \pm 0.10$ & $14.52 \pm 1.50$ & $41.33 \pm 13.10$ \\
\hline
\end{tabular}

Table 5. Composition of $\beta^{\prime}$ particle

\begin{tabular}{|c|c|c|}
\hline & at.\% & Formula \\
\hline $\mathrm{Fe}$ & 49 & \\
$\mathrm{Al}$ & 25 & \\
$\mathrm{Ti}$ & 15 & $\mathrm{Fe}_{2} \mathrm{Al} \mathrm{Ti}_{0.6} \mathrm{Cr}_{0.4}$ \\
$\mathrm{Cr}$ & 11 & \\
\hline
\end{tabular}

The results presented so far indicate that $\beta^{\prime}$ phase corresponds to the FeAl phase, with the $\mathrm{Ti}$ substituting for the $\mathrm{Al}$ (as it does in $\mathrm{Ni}_{3} \mathrm{Al}$ ). The characteristics of bonding in alloyed FeAl (B2-ordered phase) and $\mathrm{Fe}_{3} \mathrm{Al}\left(\mathrm{DO}_{3}\right.$-ordered phase) are intimately linked to the structure of compounds and the distribution of alloying atoms on the sublattices 
in these phases. This concerns mainly the $\mathrm{DO}_{3}$-ordered phase, which has several nonequivalent iron sublattices with the preference for transition metals to occupy some sites or to distribute randomly between all of them. In a completely ordered state, Al atoms occupy four sites, and Fe occupies four Fe(2) and eight Fe(1) sites. It turns out that Ti substitutes for Fe on the $\mathrm{Fe}(2)$ sites, contrary to $\mathrm{Ni}$, which substitutes for Fe on the $\mathrm{Fe}(1)$ sites $[27,28]$. Thus, the addition of Ti to the Fe-Al system can produce two different compounds. The traditional $\mathrm{Fe}_{3} \mathrm{Al}$ with $\mathrm{DO}_{3}$ structure will evolve to (Fe1$x T i x)_{3} \mathrm{Al}$, and more likely to the Heusler-type $\mathrm{Fe}_{2} \mathrm{AlTi}\left(\mathrm{L} 2_{1}\right)$, or alternatively, a Fe(Al,Ti) (B2-ordered phase) [29-31].

The HRTEM image in Fig. 7(a) shows the presence of potential $\beta^{\prime}$ particles since their size $(5-10 \mathrm{~nm})$ is in good agreement with APT results. Fig. 7(b) displays a HRTEM image of one of the particles, whose symmetry is consistent with a cubic structure oriented along [ $\left[\begin{array}{lll}0 & 1 & \overline{1}\end{array}\right]$ zone axis, see also the corresponding Fast-Fourier Transform (FFT) in Fig 7(c). The interplanar distances directly measured in the HRTEM image and in the FFT are consistent with $\mathrm{Fe}_{2} \mathrm{AlTi}$ (L21) phase, whose reported lattice parameter is $0.5879 \mathrm{~nm}$ [32], dismissing the possibility of the presence of Fe(Al,Ti) B2-ordered structure. All the $\beta^{\prime}$ particles characterized through HRTEM have the same nature.

In addition, $\beta^{\prime}$ particles are coherent with the matrix since the $(011)_{\alpha \text {-matrix }}$ are oriented in the same direction as the $(200)_{\beta^{\prime}}$. Both interplanar distances are very similar, 0.203 $\mathrm{nm}$ and $0.208 \mathrm{~nm}$ respectively. 


\section{Relationship between hardness and $\beta^{\prime}$ precipitation}

The number density $(N v)$ of the $\beta^{\prime}$ particles was obtained from the APT data by the maximum separation method (MSM) [33]. The evolution of $N v$ with time for both ageing temperatures is shown in Fig. 8(a). The relationship between Nv evolution with the progress of $\alpha-\alpha^{\prime}$ phase separation monitored by the $C r$-amplitude $\left(\Delta C_{c_{r}}\right)$ is shown in Fig. $8(b)$. The evolution of the radius of the $\beta^{\prime}$ precipitates with ageing time, as determined from the MSM, is shown in Fig. 8(c). For the same ageing times, the particles formed during ageing at $475{ }^{\circ} \mathrm{C}$ are significantly coarser than those formed at $435{ }^{\circ} \mathrm{C}$, which is consistent with the lower Nv obtained.

As indicated in Fig. 8(d), the increase in $N v$ is strongly correlated with the increase in hardness $(\Delta H v)$ for the material aged at $435^{\circ} \mathrm{C}$, but not the material aged at $475{ }^{\circ} \mathrm{C}$, where the number density of $\beta^{\prime}$ precipitates is significantly lower. Therefore, it is a sensible assumption that the hardness increase observed in Fig. 1 might be related with the $\beta^{\prime}$ precipitates.

The strengthening of the material aged at $435{ }^{\circ} \mathrm{C}$ is a combination of two factors: the $\alpha-\alpha^{\prime}$ phase separation and the $\beta^{\prime}$ precipitates. Conversely, due to the lower $N v$ of the $\beta^{\prime}$ precipitates in the material aged at $475{ }^{\circ} \mathrm{C}$, the strengthening mechanism is mainly due to $\alpha-\alpha^{\prime}$ phase separation through the modulus effect. The hardening mechanism during $\alpha-\alpha^{\prime}$ and $\alpha-\beta^{\prime}$ precipitation is basically different. The effect of the phase separation process on strengthening is twofold: firstly, the $\alpha-\alpha^{\prime}$ phase separation induces a stress field (misfit between the $\alpha$ and $\alpha^{\prime}$ phases) that hinders dislocations from propagating, as described by Cahn [34]. A dislocation in a phase separated 
structure experiences a force from the internal stresses due to periodic variations of the lattice parameter. Secondly, the spatial variation in the Young's modulus associated with the composition modulation (modulus effect) is also considered as an obstacle for the motion of dislocations.

On the other hand, the hardening associated with the $\beta^{\prime}$ precipitates is due to the interaction of those coherent intermetallic precipitates with dislocations. These $\beta^{\prime}$ particles are likely to provide significant resistance to dislocation glide in that they pin dislocation lines [35]. The nature of the attraction between dislocations and nanoparticles may be influenced by several factors including, but not limited to, modulus relative to the matrix, particle dimensions and distributions (size, shape, and spacing), interfacial structure and coherency with the matrix.

\section{Coexistent nanoscale $\alpha$ - $\alpha^{\prime}$ and $\alpha$ - $\beta^{\prime}$ precipitation processes}

The $\mathrm{Cr}$ and Ti APT iso-concentration surfaces after ageing at $435^{\circ} \mathrm{C}$ for several times are shown in Fig. 9a. From this figure the interconnectivity between both isoconcentration surfaces, and $\beta^{\prime}$ phase formation around $\alpha^{\prime}$ phase for all the isothermal times can be appreciated. A closer observation of all the conditions analyzed, allow us to conclude that $\beta^{\prime}$ phase appears after some $\alpha^{\prime}$ phase has already formed in the microstructure, although the lack of short time annealing treatments in the study does not allow us to absolutely dismiss the possibility of both phases forming simultaneously. The $\beta^{\prime}$ particles are always formed on the surface of $\alpha^{\prime}$ phase. It was not possible to find isolated $\beta^{\prime}$ particles in the matrix. 
On the basis that $\alpha-\alpha^{\prime}$ phase separation is a spinodal process, the $\mathrm{Cr}$-enrichment of $\alpha^{\prime}$ particles starts at the beginning of the ageing treatment. Such an increase in $\mathrm{Cr}$ will promote the depletion of other elements, such as $\mathrm{Al}$ and $\mathrm{Ti}$, which presents low solubility in the $\alpha^{\prime}$ phase. Conversely, it is likely that $\beta^{\prime}$ phase is formed under a clustering and ordering mechanism [36]. Therefore, there will be a period of time before the increase in Ti level in $\beta^{\prime}$ particle (due to kinetics) is observed. This is consistent with the results presented in Table 2, where the Ti content, which drives the nucleation of $\beta^{\prime}$ phase, will be depleted from $\alpha^{\prime}$ at later stages of $\alpha$ - $\alpha^{\prime}$ phase separation.

The nucleus size for $\beta^{\prime}$ precipitates $\left(r^{*}\right)$ can be determined from heterophase fluctuations considered by the classical theory of nucleation. Fluctuations in density and concentration lead to small volumes of $\alpha$ phase acquiring different new atomic arrangements, thus a local $\alpha-\beta^{\prime}$ phase transformation occurs [37].

The overall driving force for the nucleation to occur is provided by the difference in the free energies of the initial and final states of the assembly. The volume free energy of the nucleus and that of the initial phase it is replacing must be considered, along with the energies of the new surfaces created between the two phases. If the nucleus is constrained by the phase in which it nucleates, then there will be an additional strain energy component to the overall free energy. In this study, because of the coherency observed between $\beta^{\prime}$ precipitates and $\alpha$ matrix (Fig. 7(a)), this term is considered negligible. Assuming a spherical nucleus of radius $r$, the net free energy change is [38]:

$$
\Delta G=-\frac{4 \pi}{3} r^{3} \Delta G_{V}+4 \pi r^{2} \sigma^{\beta \alpha},
$$


where $\sigma^{\beta \alpha}$ is the interfacial energy per unit area between $\beta$ precipitates and $\alpha$ matrix and $\Delta G_{V}$ is the magnitude of the chemical driving force per unit volume for formation of $\beta$ phase from $\alpha$ phase.

The critical free energy barrier to nucleation that must be supplied by thermal fluctuations, $G^{*}$, occurs at a critical radius $r^{*}$ when the free energy change $\Delta G$ is a maximum. Thus:

$\frac{d(\Delta G)}{d r}=-4 \pi r^{2}+\Delta G_{V}++8 \pi r \sigma^{\beta \alpha}=0$

Therefore,

$r^{*}=\frac{2 \sigma^{\beta \alpha}}{\Delta G_{V}}$

Assuming a value of $\sigma^{\beta \alpha}=0.15 \mathrm{~J} \mathrm{~m}^{-2}$ derived by first principle calculations by Matysina et al. for Fe-FeAl system [39], and values of $\Delta G_{V}$ of $5.82 \times 10^{8} \mathrm{~J}^{\mathrm{m}} \mathrm{m}^{-3}$ for $435^{\circ} \mathrm{C}$ and $6.18 \times 10^{8} \mathrm{~J}^{\mathrm{m}} \mathrm{m}^{-3}$ for $475^{\circ} \mathrm{C}$ obtained from MT-DATA calculations, a value of $r^{*} \sim 0.5 \mathrm{~nm}$ is obtained for both temperatures. This is consistent with experimental values presented in Fig. 8(c).

All these observations lead us to postulate two different situations to disclose if formation of $\alpha^{\prime}$ and $\beta^{\prime}$ phases are related:

Case 1: The diffusion rates of Ti and/or Al in the Fe-rich matrix $\alpha$ and the Cr-rich $\alpha^{\prime}$ phase are equivalent. The $\alpha-\alpha^{\prime}$ phase separation proceeds via spinodal decomposition first, where $\mathrm{Ti}$ and $\mathrm{Al}$ are rejected from the evolving $\alpha^{\prime}$ and then reach a supersaturated level in the $\alpha$ matrix. This allows the $\beta^{\prime}$ to precipitate on or near the $\alpha-$ 
$\alpha^{\prime}$ interface, as that is where the Ti and Al concentration are highest. In this sense, both $\alpha^{\prime}$ and $\beta^{\prime}$ formation occurs simultaneously, i.e. both processes are linked. This situation depends, to some extent, on the fact diffusion rates of $\mathrm{Ti}$ and $\mathrm{Al}$ in $\alpha$ and $\alpha^{\prime}$ phase are the same order of magnitude at each of the temperatures studied, i.e. at 435 and $475^{\circ} \mathrm{C}$.

Case 2: Ti and/or Al diffusion rates in the matrix ( $\alpha$ phase) are faster than that in the $\alpha^{\prime}$ phase. The $\alpha-\alpha^{\prime}$ phase separation starts, but the amount of Ti rejected from the $\alpha^{\prime}$ phase does not play a role, and the $\beta^{\prime}$ precipitates are unrelated to the spinodal reaction. This should lead to the formation of independent $\beta^{\prime}$ precipitates in the matrix. The fact that they are attached to the $\alpha-\alpha^{\prime}$ interface might be due to $\alpha-\alpha^{\prime}$ interfaces as preferential nucleation sites.

The chemical diffusion coefficients of $\mathrm{Ti}$ and $\mathrm{Al}$ in body centered cubic $\mathrm{Fe}$ and in $\mathrm{Cr}$, calculated at $450^{\circ} \mathrm{C}$ using DICTRAC with MOB2 database, are shown in Fig. 9(b). The Ti diffusion coefficient at this temperature is several orders of magnitude lower in $\mathrm{Cr}$ than Fe. Therefore, Ti diffusion in the $\alpha^{\prime}$-phase should be slower than in the $\alpha$-phase. This trend would suggest that there should not be a Ti enrichment at the coherent $\alpha-\alpha^{\prime}$ interface, as Ti should be able to diffuse away in the $\alpha$ phase after being rejected from the $\alpha^{\prime}$ phase.

On the other hand, the behavior of Al is significantly different. Figure 9(c) indicates that the Al diffusion coefficient in $\alpha^{\prime}$ phase is faster than in $\alpha$ phase. Therefore, Al will tend to accumulate at the $\alpha$ - $\alpha^{\prime}$ interface after Al diffuses away from $\mathrm{Cr}$-rich phase (very low solubility) during $\alpha-\alpha$ 'phase separation process. Because of the higher diffusion coefficient of $\mathrm{Al}$ than $\mathrm{Ti}$, once $\mathrm{Al}$ starts building up at the $\alpha$ - $\alpha^{\prime}$ interface, Ti rejected 
from $\alpha^{\prime}$ phase will be trapped in this Al-enriched zone nearby the interface. Hence, the $\beta^{\prime}$ phase will nucleate. This supports the idea that both processes, i.e., $\alpha-\alpha^{\prime}$ phase separation and $\beta^{\prime}$ precipitation, are not independent processes as indicated in Case 1 , which would be also consistent with the results shown in Fig. 9(b) and Fig 9(c).

\section{Conclusions}

1. A TiAl-rich phase, named $\beta^{\prime}$ was characterized by APT. The composition of this intermetallic phase was determined to be $\mathrm{Fe}_{2} \mathrm{Al} \mathrm{Ti}_{0.6} \mathrm{Cr}_{0.4}$ from analysis of proximity histograms. HRTEM analysis established that those particles were a cubic phase corresponding to the Heusler-type Fe ${ }_{2} \mathrm{AlTi}\left(\mathrm{L}_{2}{ }_{1}\right)$. The $\beta^{\prime}$ particles are always oriented along [ $\left[\begin{array}{lll}0 & 1 & 1\end{array}\right]$ zone axis and are coherent with the $\alpha$-Fe matrix.

2. The steady-state hardness increase recorded during ageing at both 475 and 435 ${ }^{\circ} \mathrm{C}$ could be explained on the basis of the $\alpha-\alpha$, phase separation through the modulus effect. The effect of the phase separation process on strengthening is twofold: firstly, the $\alpha-\alpha^{\prime}$ phase separation induces a stress field (misfit between the $\alpha$ and $\alpha^{\prime}$ phases) that hinders dislocations from propagating, as described by Cahn [34]. A dislocation in a phase separated structure experiences a force from the internal stresses due to periodic variations of the lattice parameter. Secondly, the spatial variation in the Young's modulus associated with the composition modulation (modulus effect) is also considered as an obstacle for the motion of dislocations. 
3. The abnormal hardness increase recorded during ageing at $435{ }^{\circ} \mathrm{C}$ could be explained on the basis of the precipitation of intermetallic $\beta^{\prime}$ particles. The hardening during $\beta^{\prime}$ precipitation is due the interaction of those intermetallic precipitates with dislocations. The $\beta^{\prime}$ particles are likely to provide significant resistance to dislocation glide in that they pin dislocation lines. However, the lack of abnormal hardening at $475^{\circ} \mathrm{C}$ might be due to the low Nv of $\beta^{\prime}$ particles, and hence the main hardening mechanism at this temperature may be due to $\alpha-\alpha^{\prime}$ phase separation through the modulus effect.

4. The significant differences in $\mathrm{Ti}$ and $\mathrm{Al}$ diffusion coefficients in $\mathrm{Fe}$ - and $\mathrm{Cr}$ matrix, in the temperature range of 435 and $475{ }^{\circ} \mathrm{C}$, indicate that there is a hierarchy in the simultaneous formation of $\alpha^{\prime}$ and $\beta^{\prime}$ phases during isothermal annealing. The fact that $\beta^{\prime}$ precipitates are attached to the $\alpha-\alpha^{\prime}$ interface might be due to a preferential nucleation site as a consequence of the Al enrichment at the interface because of the $\alpha-\alpha^{\prime}$ phase separation.

\section{Acknowledgements}

PM $2000^{\text {TM }}$ is a trademark of Plansee $\mathrm{GmbH}$. LEAP ${ }^{\circledR}$ is a registered trademark of

CAMECA Instruments Inc. CC and JC acknowledge financial support to Spanish Ministerio de Ciencia e Innovación through in the form of a Coordinate Project in the Energy Area of Plan Nacional 2009 (ENE2009-13766-C04-01). Atom probe tomography (MKM) was supported through a user project supported by ORNL's Center for Nanophase Materials Sciences (CNMS), which is sponsored by the Scientific User Facilities Division, Office of Basic Energy Sciences, U.S. Department of Energy. The 
authors acknowledge Dr. J. Aldazabal and J.C. Rodriguez of CEIT for performing the DICTRA calculations. 


\section{Figure Captions}

Figure 1. Incremental hardness evolution $(\Delta \mathrm{HV})$ during ageing time at 435 and $475{ }^{\circ} \mathrm{C}$ in PM 2000.

Figure 2. 30\% $\mathrm{Cr}$ isoconcentration surfaces for 500 and $3600 \mathrm{~h}$ during ageing at (a) $435^{\circ} \mathrm{C}$ and (b) $475^{\circ} \mathrm{C}$.

Figure 3. a) Calculated miscibility gap where the composition obtained from APT for $\alpha$ and $\alpha^{\prime}$ particles with corresponding ageing time in hours are presented. b) Comparison of $\alpha^{\prime}$ volume fraction evolution with ageing time derived from lever rule (LR) from APT data and theoretical calculation from miscibility gap (MG).

Figure 4. Lever rule diagram. The nominal concentration $\left(\mathrm{C}_{\text {alloy }}\right)$ for each element $(\mathrm{Cr}$, $\mathrm{Fe}, \mathrm{Al}$ and $\mathrm{Ti}$ ) minus the solute content in the $\alpha$ matrix $\left(\mathrm{C}_{\mathrm{m}}\right)$ is plotted as a function of the difference in composition between the $\alpha^{\prime}$ precipitate and the $\alpha$ matrix $\left(C_{p}-C_{m}\right)$. The slope gives the molar fraction of $\alpha^{\prime}$ present in the alloy (After [21]).

Figure 5. Development of autocorrelation function analysis of APT data of PM 2000 for $100 \mathrm{~h}, 1008 \mathrm{~h}, 2040 \mathrm{~h}$, and $3600 \mathrm{~h}$ aged at (a) $435^{\circ} \mathrm{C}$ and (b) $475^{\circ} \mathrm{C}$.

Figure 6. Atom maps after ageing at (a) 435 and (b) $475^{\circ} \mathrm{C}$ for $3600 \mathrm{~h}$ and the corresponding composition profile across $\alpha^{\prime}$-phase and $\beta^{\prime}$ precipitate. The $\beta^{\prime}$ volume fraction according to lever rule (After [21]) is shown in (c).

Figure 7. a) HRTEM image showing potential $\beta^{\prime}$ particles. b) HRTEM image showing the coherency between the matrix and the analyzed particle and c) FFT pattern for the area delimited by the white rectangle in (b) where the $\beta^{\prime}$ particle is identified.

Figure 8. Evolution of number density (Nv) of $\beta^{\prime}$ particles with (a) ageing time, (b) the extent of $\alpha-\alpha^{\prime}$ phase separation monitored by $\mathrm{Cr}$-composition amplitude $\left(\Delta C_{\mathrm{cr}}\right)$. The coarsening of $\beta^{\prime}$ particles is shown in (c), and (d) illustrates the correlation between $N v$ and $\Delta H v$ for ageing temperatures of 435 and $475^{\circ} \mathrm{C}$.

Figure 9. a) Iso-concentration ( 30 at.\% $\mathrm{Cr}$ and 3 at\% $\mathrm{Ti}$ ) surfaces after annealing at $435{ }^{\circ} \mathrm{C}$ for the time shown. Evolution of (b) Ti and (c) Al diffusion in BCC-Fe and BCC-Cr matrix with $\mathrm{Ti}$ and $\mathrm{Al}$ concentrations calculated at $450{ }^{\circ} \mathrm{C}$. Dashed line indicates the $\mathrm{Ti}$ and $\mathrm{Al}$ concentrations in $\beta^{\prime}$ particles. 


\section{References}

[1] Liu Y, Fang J, Liu D, Lu Z, Liu F, Chen S, Liu CT. Formation of oxides particles in ferritic steel by using gas-atomized powder J. Nucl. Mater. 2010;396:86.

[2] Wright IG, Gibbons TB. Recent developments in gas turbine materials and technology and their implications for syngas firing Int. J. Hydrogen Energy 2007;32:3610.

[3] Zinkle SJ. Advanced materials for fusion technology Fusion Eng. Des. 2005;74:31.

[4] Wong CPC, Malang S, Sawan M, Sviatoslavsky I, Mogahed E, Smolentsev S, Majumdar S, Merrill B, Mattas R, Friend M, Bolin J, Sharafat S. Molten salt self-cooled solid first wall and blanket design based on advanced ferritic steel Fusion Eng. Des. 2004;72:245.

[5] Gleiter $\mathrm{H}$. Nanostructured materials: basic concepts and microstructure Acta Mater. 2000;48:1.

[6] Andrievskii RA, Glezer AM. Size effects in nanocrystalline materials: I. Structure characteristics, thermodynamics, phase equilibria, and transport phenomena Phys. Met. Metall. 1999;88:45.

[7] Malow TR, Koch CC. Grain growth in nanocrystalline iron prepared by mechanical attrition Acta Mater. 1997;45:2177.

[8] Gottstein G, Shvindlerman LS. Triple junction drag and grain growth in 2D polycrystals Acta Mater. 2002;50:703.

[9] Capdevila C, Chen YL, Lassen NCK, Jones AR, Bhadeshia HKDH. Heterogeneous deformation and recrystallisation of iron base oxide dispersion strengthened PM2000 alloy Mater. Sci. Technol. 2001;17:693.

[10] Capdevila C, Miller U, Jelenak H, Bhadeshia HKDH. Strain heterogeneity and the production of coarse grains in mechanically alloyed iron-based PM2000 alloy Mater. Sci. Eng. A 2001;316:161.

[11] Capdevila Montes C, Bhadeshia HKDH. Influence of Deformation on Recrystallization of an Yttrium Oxide Dispersion-Strengthened Iron Alloy (PM2000) Adv. Eng. Mater. 2003;5:232.

[12] Miller MK. Atom probe tomography : analysis at the atomic level. New York: Kluwer Academic / Plenum Publishers, 2000.

[13] Capdevila C, Miller MK, Russell KF. Aluminum partitioning during phase separation in Fe-20\%Cr-6\%Al ODS alloy J. Mater. Sci. 2008;43:3889.

[14] Capdevila C, Miller MK, Russell KF, Chao J, González-Carrasco JL. Phase separation in PM $2000^{\mathrm{TM}}$ Fe-base ODS alloy: Experimental study at the atomic level Mater. Sci. Eng. A 2008;490:277.

[15] Capdevila C, Miller MK, Chao J. Phase separation kinetics in a Fe-Cr-Al alloy Acta Mater. 2012;60:4673.

[16] Capdevila C, Miller MK, Toda I, Chao J. Influence of the $\alpha-\alpha^{\prime}$ phase separation on the tensile properties of Fe-base ODS PM 2000 alloy Mater. Sci. Eng. A 2010;527:7931.

[17] Lacasta AM, Hernandez-Machado A, Sancho JM, Toral R. Domain growth in binary mixtures at low temperatures Physical Review B 1992;45:5276.

[18] Hellman OC, Vandenbroucke JA, Rüsing J, Isheim D, Seidman DN. Analysis of three-dimensional atom-probe data by the proximity histogram Microsc. Microanal. 2000;6:437. 
[19] Paxton H, Kunitake T. Diffusion in the Iron-Chromium System Trans. Metall. Soc. AIME 1960;218:1003.

[20] MT-DATA. Phase diagram Calculation software. Teddington, UK: National Physical Laboratory, 2003.

[21] Blavette D, Cadel E, Deconihout B. Role of the atom probe in the study of nickel-based superalloys Mater. Charact. 2000;44:133.

[22] Stuart A, Kendall M, Ord J. The advanced theory of statistics. London: Giffin and Box, 1983.

[23] Hetherington MG, Hyde JM, Miller MK, Smith GDW. Measurement of the amplitude of a spinodal Surf. Sci. 1991;246:304.

[24] Langer JS, Bar-On M, Miller HD. New computational method in the theory of spinodal decomposition Physical Review A 1975;11:1417.

[25] Hetherington MG, Miller M, K. Statical analysis of the early stages of phase decomposition by atom probe J. Phys. Colloques 1988;49:427.

[26] Ardell AJ. Temporal behavior of the number density of particles during Ostwald ripening Mater. Sci. Eng. A 1997;238:108.

[27] Kao CR, Pike LM, Chen SL, Chang YA. Site preference of substitutional additions to triple-defect B2 intermetallic compounds Intermetallics 1994;2:235.

[28] Kim SM, Morris DG. Long range order and vacancy properties in Al-rich Fe3Al and Fe3Al(Cr) alloys Acta Mater. 1998;46:2587.

[29] Nishino Y. Unusual electron transport in Heusler-type Fe2VAl compound Intermetallics 2000;8:1233.

[30] Prakash U, Sauthoff G. Structure and properties of Fe-Al-Ti intermetallic alloys Intermetallics 2001;9:107.

[31] Zhu S-M, Iwasaki K. Characterization of mechanically alloyed ternary Fe-Ti-Al powders Mater. Sci. Eng. A 1999;270:170.

[32] Buschow KHJ, van Engen PG. Magnetic and magneto-optical properties of heusler alloys based on aluminium and gallium J. Magn. Magn. Mater. 1981;25:90.

[33] Miller MK, Hyde JM, Hetherington MG, Cerezo A, Smith GDW, Elliott CM. Spinodal decomposition in Fe-Cr alloys: Experimental study at the atomic level and comparison with computer models-I. Introduction and methodology Acta Metall. Mater. 1995;43:3385.

[34] Cahn JW. Hardening by spinodal decomposition Acta Metall. 1963;11:1275.

[35] Brandes MC, Kovarik L, Miller MK, Mills MJ. Morphology, structure, and chemistry of nanoclusters in a mechanically alloyed nanostructured ferritic steel $\mathrm{J}$. Mater. Sci. 2012;47:3913.

[36] De Fontaine D. An analysis of clustering and ordering in multicomponent solid solutions-I. Stability criteria J. Phys. Chem. Solids 1972;33:297.

[37] Christian JW. The theory of transformations in metals and alloys Oxford: Elsevier, 2002.

[38] Christian JW. Chapter 10 - The Classical Theory of Nucleation. In: Christian JW, editor. The Theory of Transformations in Metals and Alloys. Oxford: Pergamon, 2002. p.422.

[39] Matysina ZA, Pogorelova OS, Zaginaichenko SY, Schur DV. The surface energy of crystalline CuZn and FeAl alloys J. Phys. Chem. Solids 1995;56:9. 
a)

$$
500 \mathrm{~h}
$$

b)
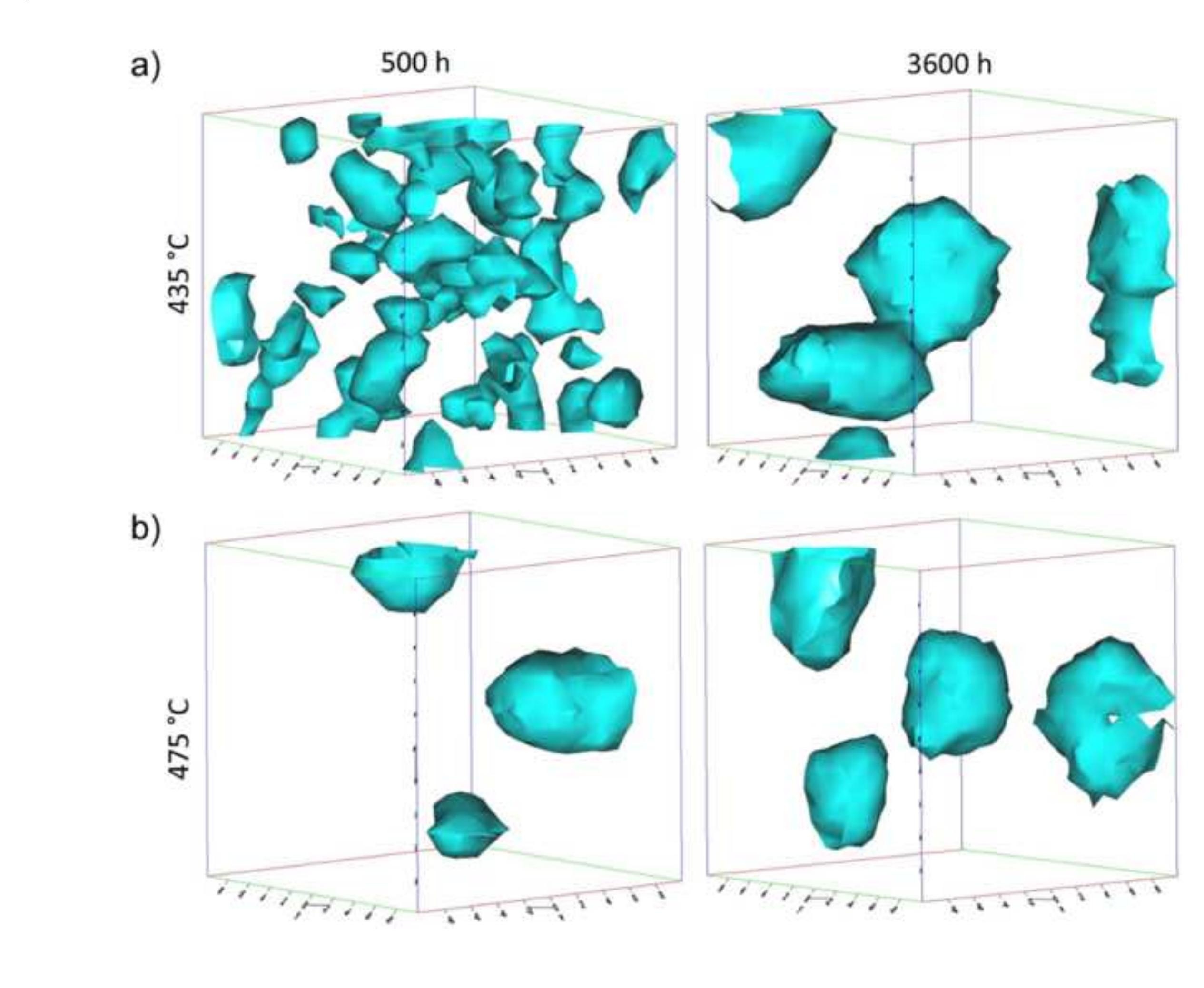

$3600 \mathrm{~h}$

.
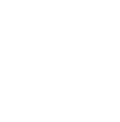

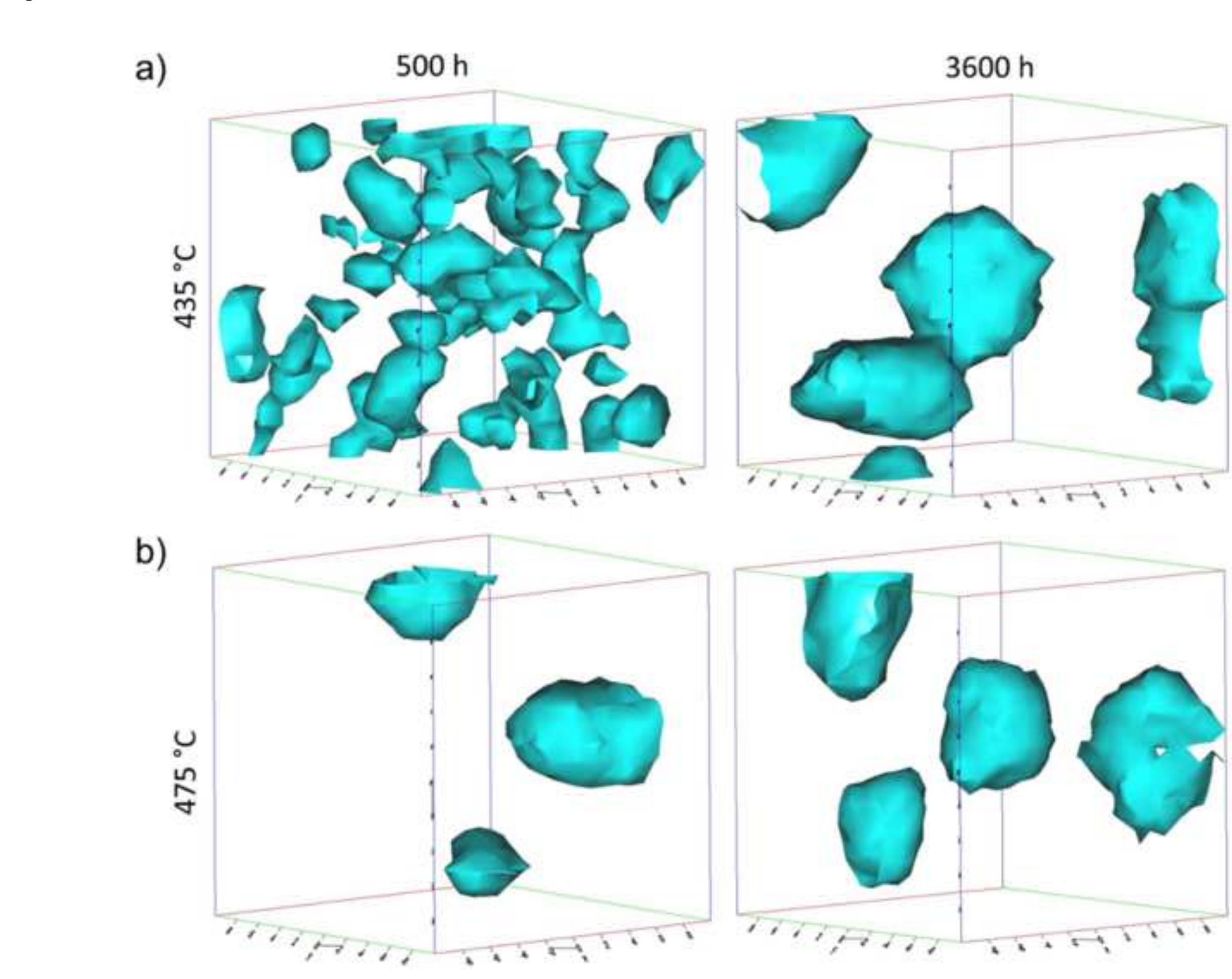

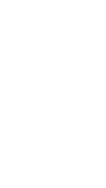

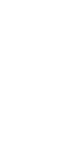


a)

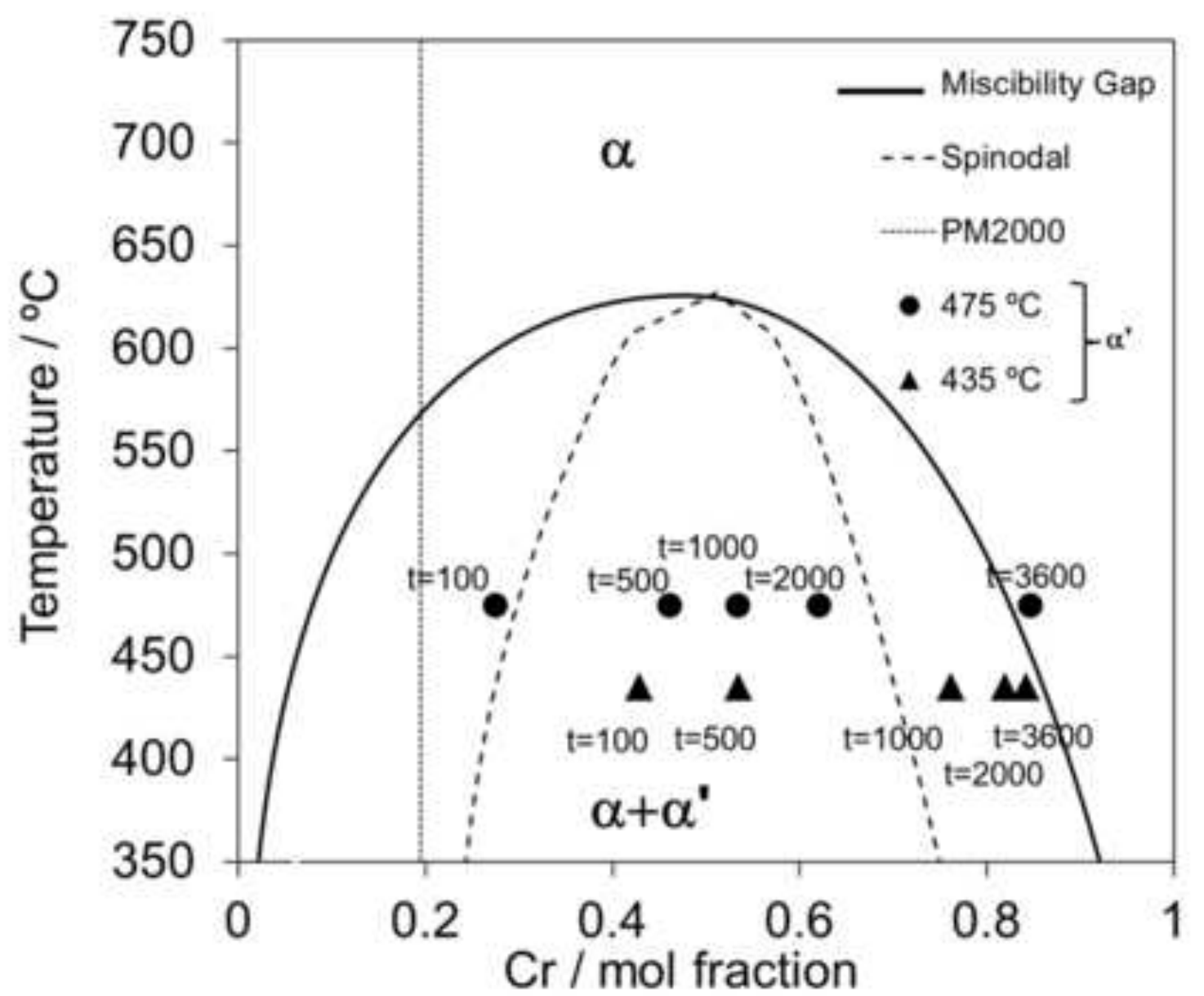

b)

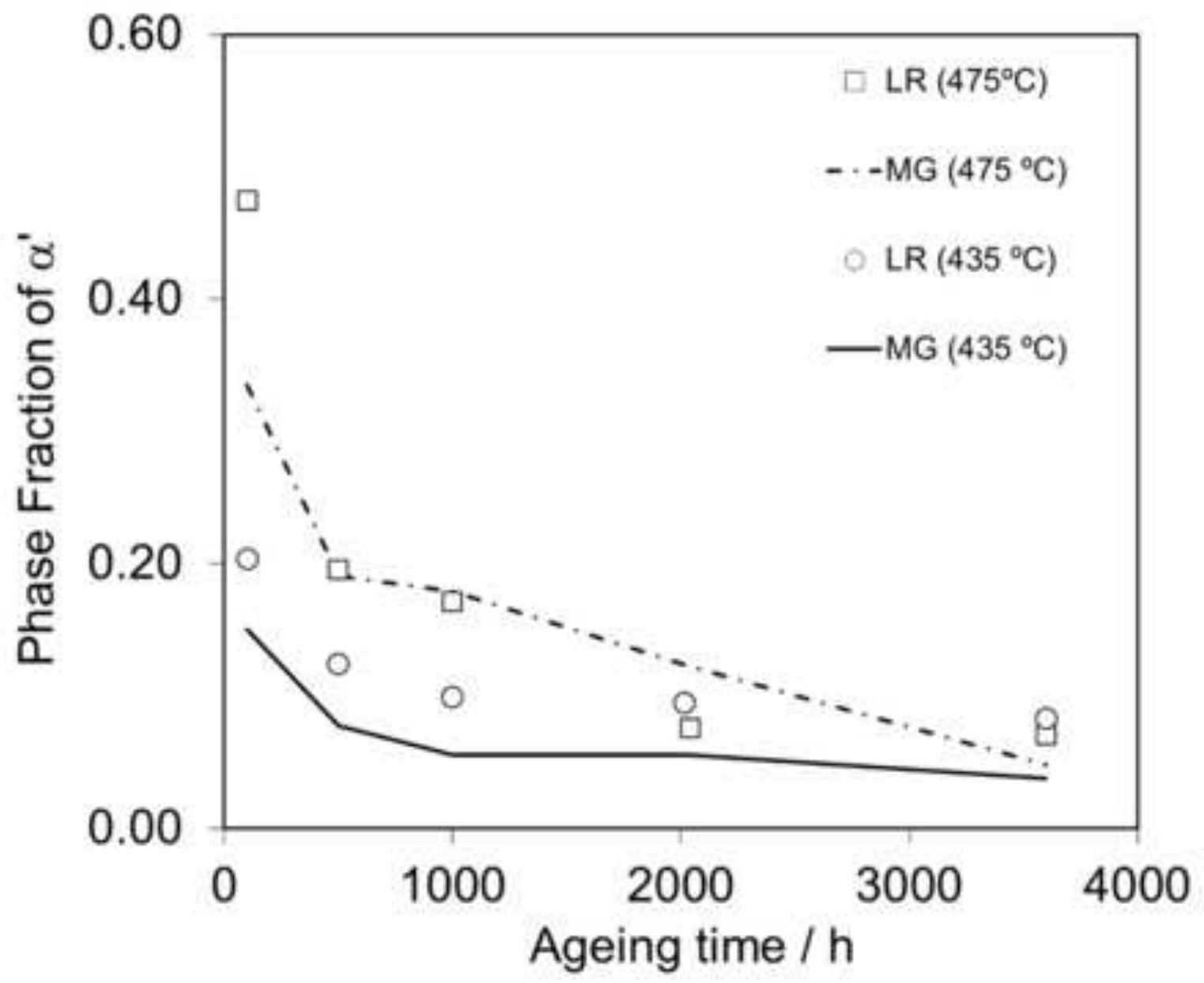


a) $3600 \mathrm{CrFe} \mathrm{Al} \mathrm{Ti}$ $2040 \mathrm{~h} \times \mathbf{x} \times \mathrm{x}$ $1000 \mathrm{~h}+\mathbf{t}+$ + $500 \mathrm{~h} \Delta \Delta \Delta \Delta$ $100 \mathrm{~h}$
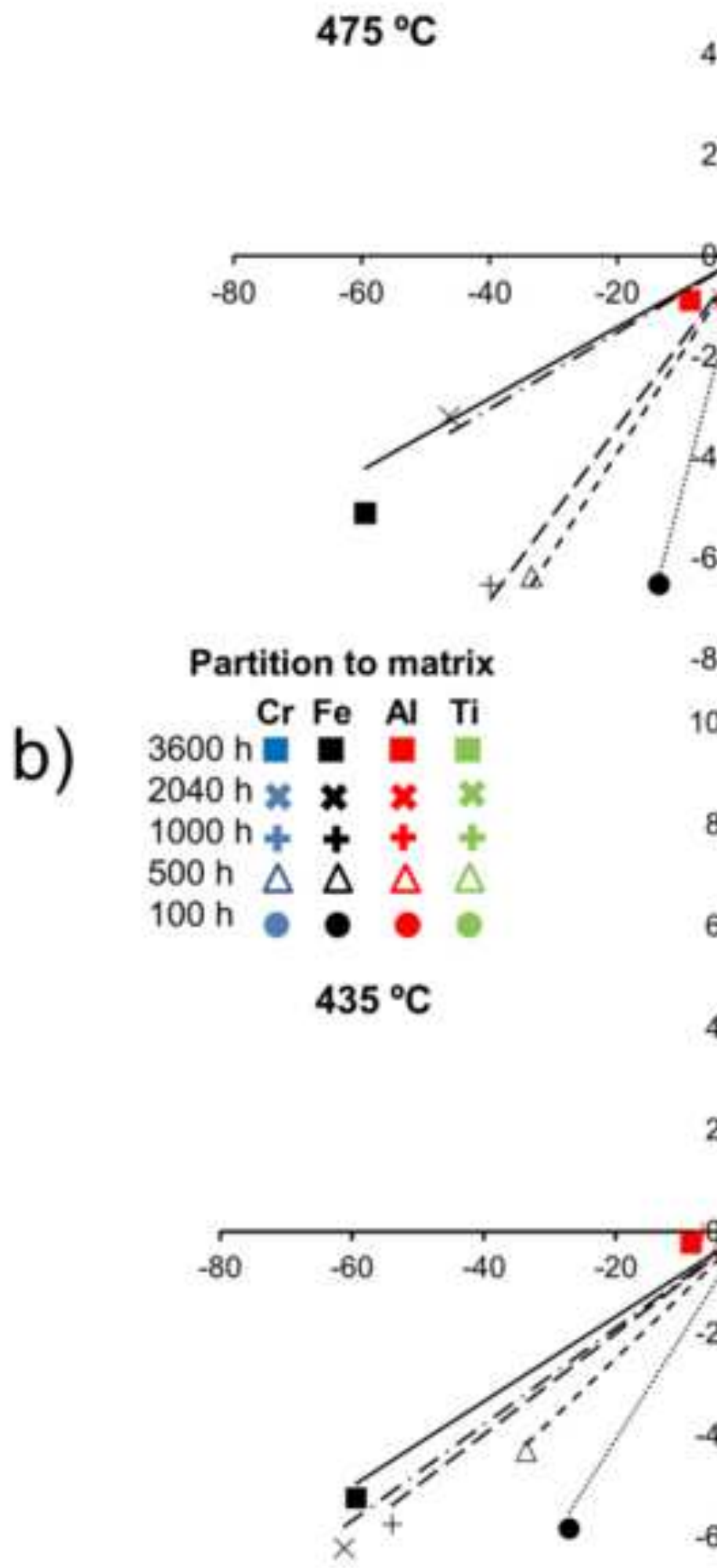

10

8

$\begin{array}{rl}R^{2}=0.9978 & y=0.4713 x \\ R^{2}=0.4746 x ; & ;\end{array}$

6

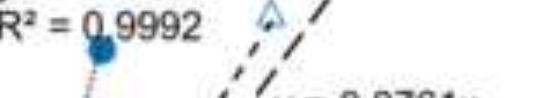

Partition to precipitate

4

$2+1$
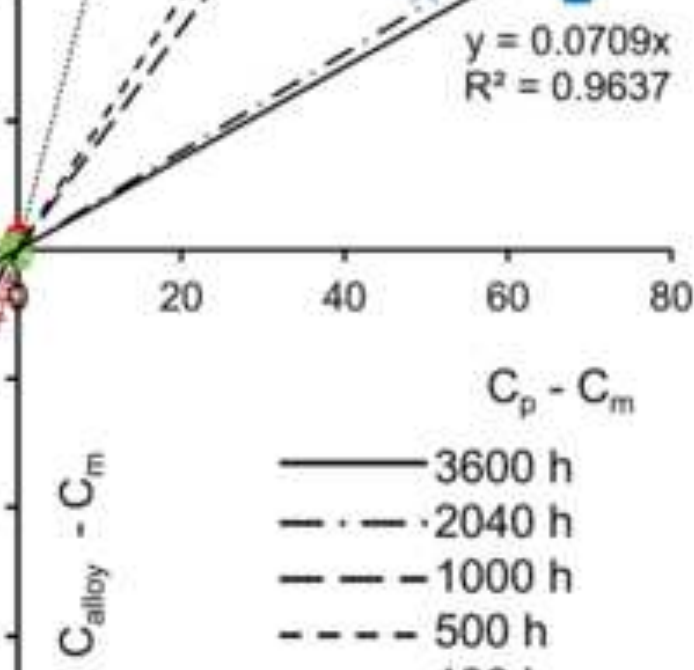

E $3600 \mathrm{~h}$

$-\cdot-2040 \mathrm{~h}$

흘 - - $1000 \mathrm{~h}$

- - - $500 \mathrm{~h}$
Partition to matrix

$-8$
............... $100 \mathrm{~h}$

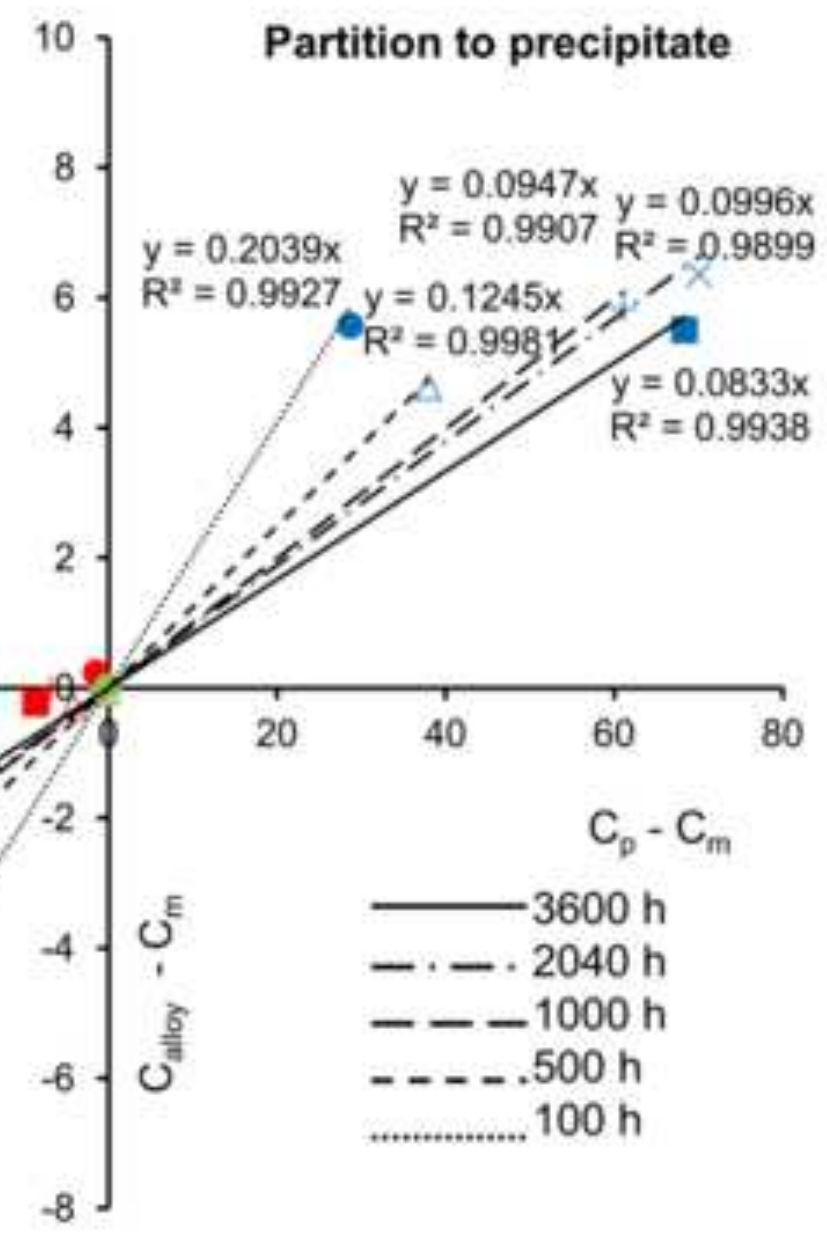


Figure 5

a)

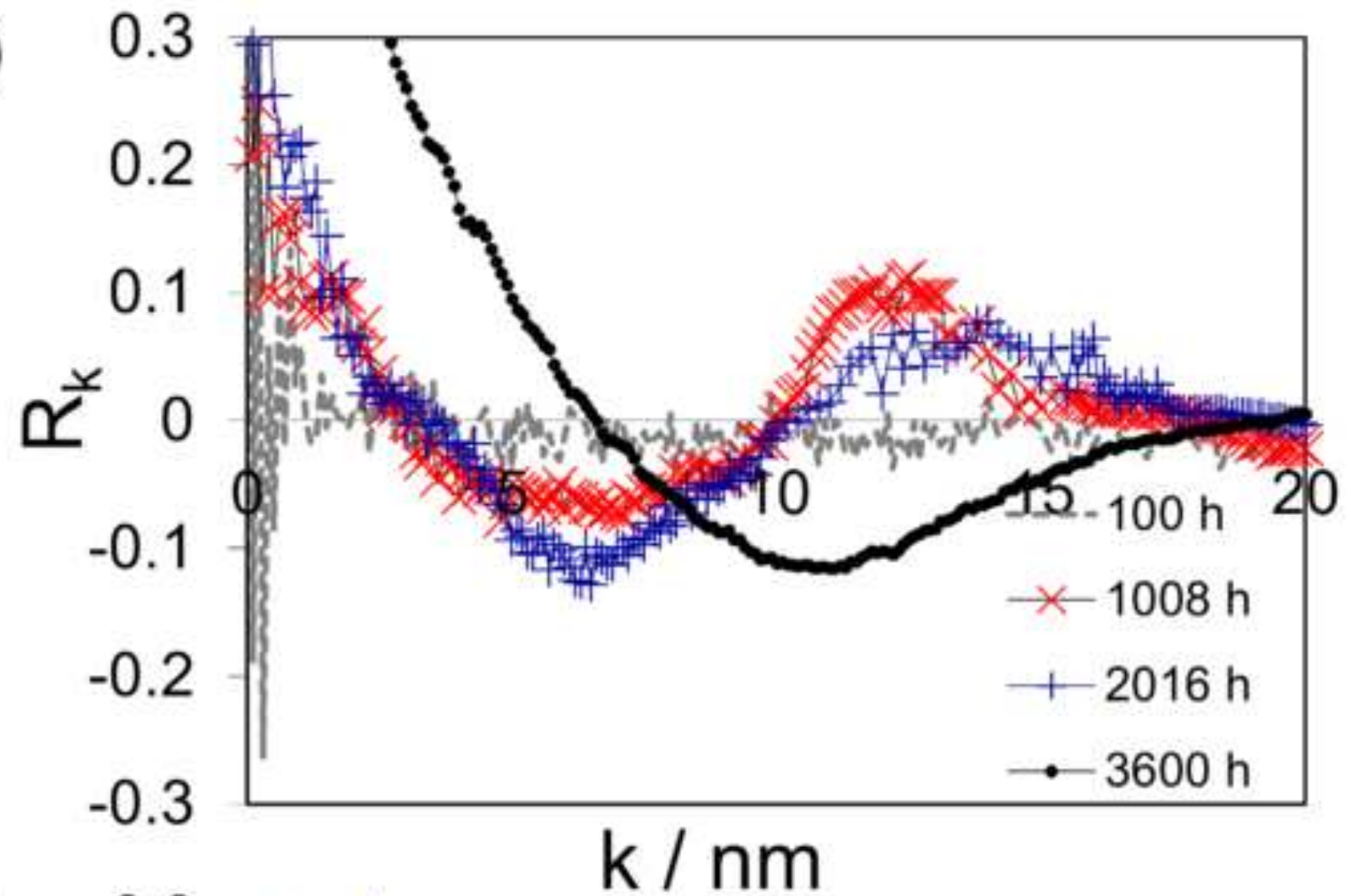

b)

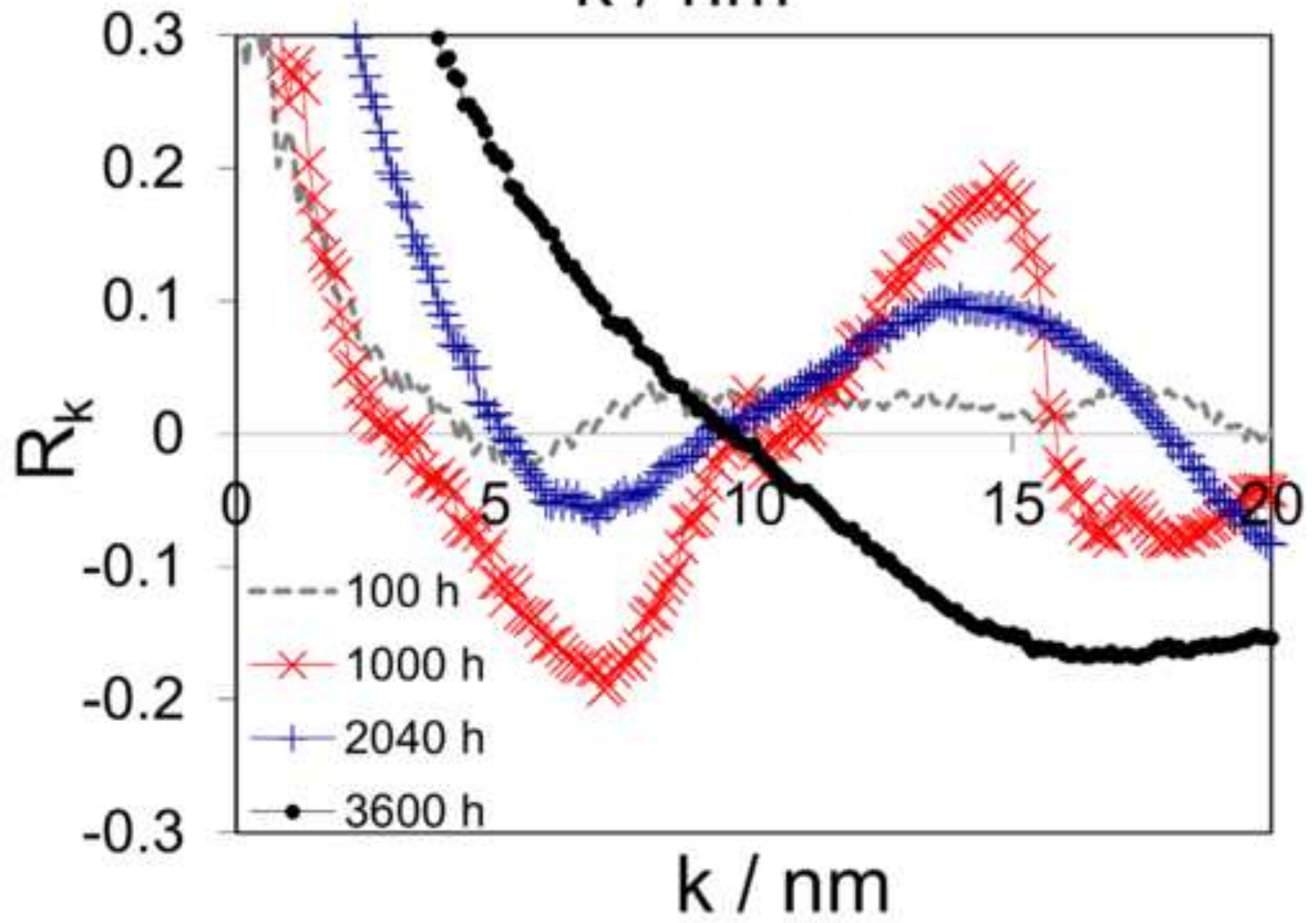


a)

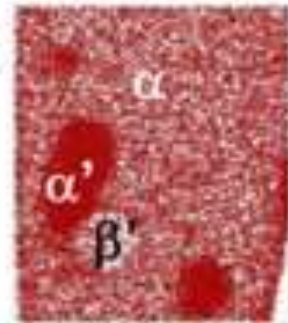

Cr

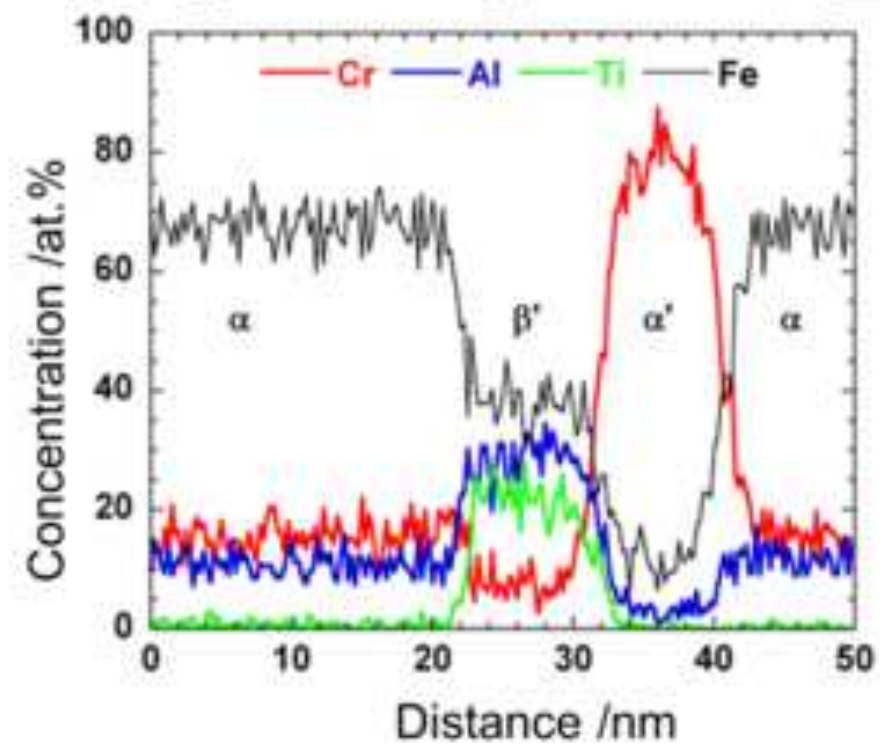

c)

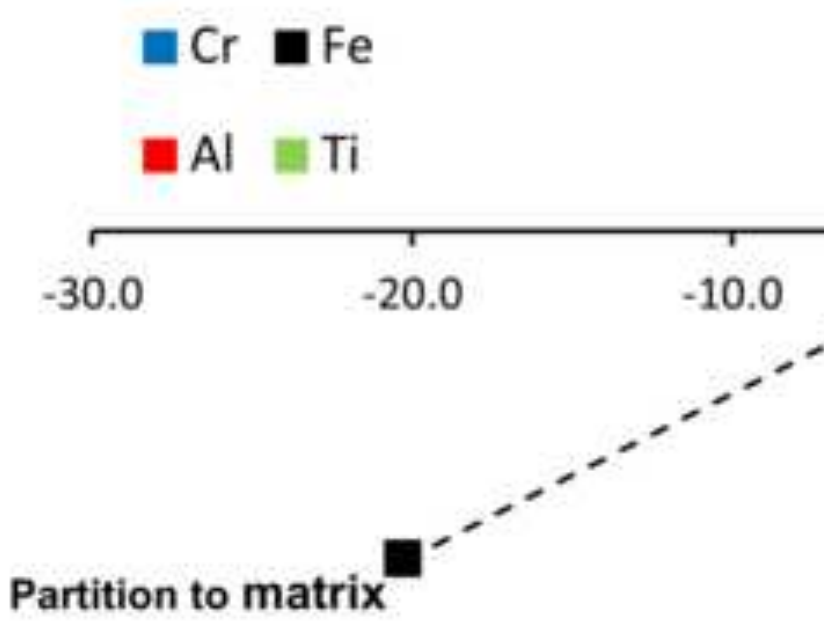

b)
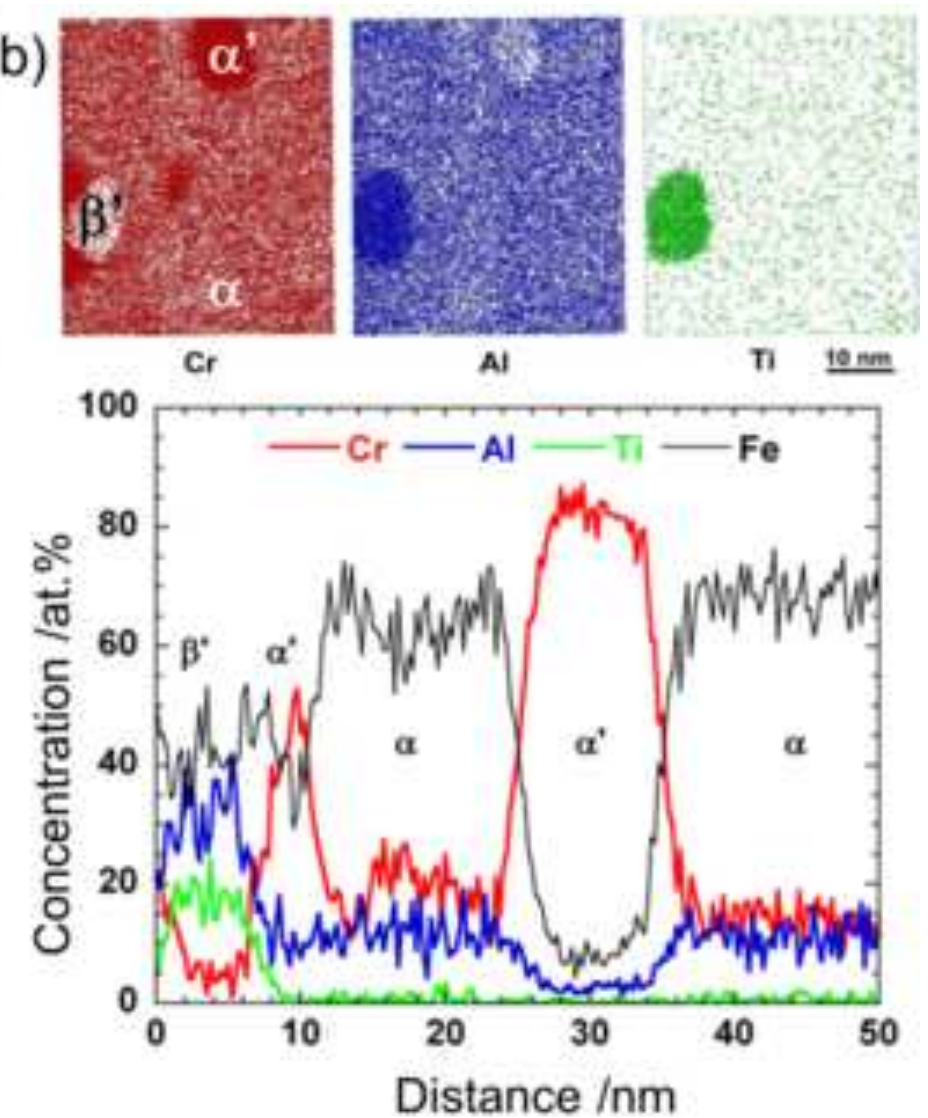

Distance $/ \mathrm{nm}$

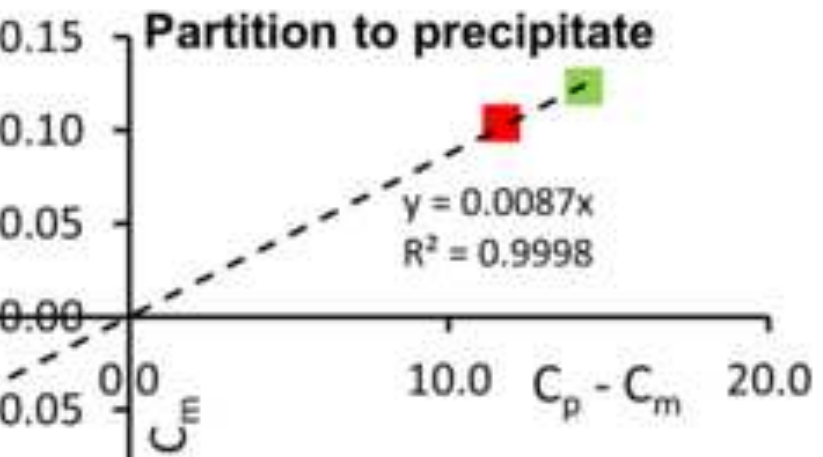

$2016 \mathrm{~h}$ at $435^{\circ} \mathrm{C}$

Averaged over 73 precipitates 
a)

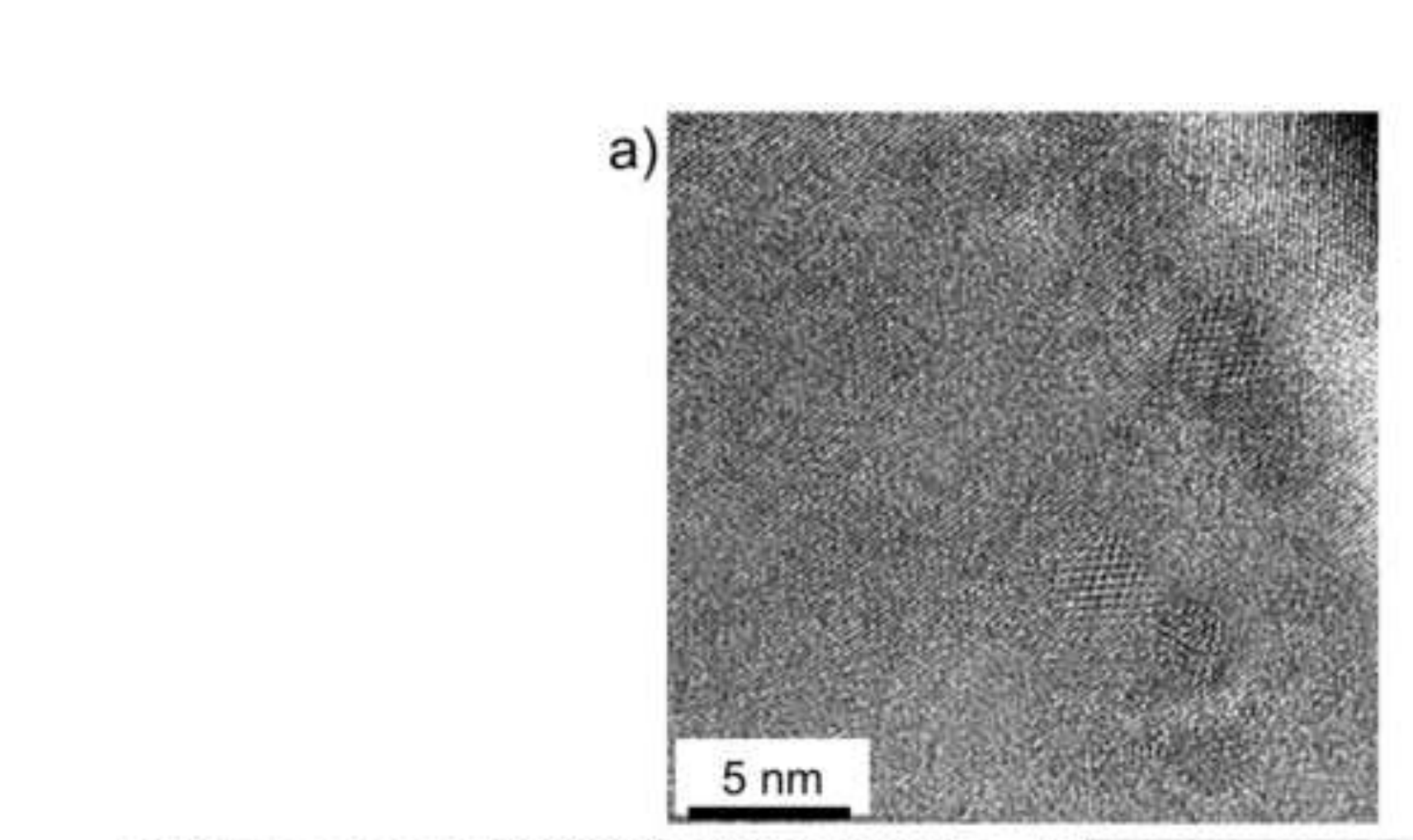

b)

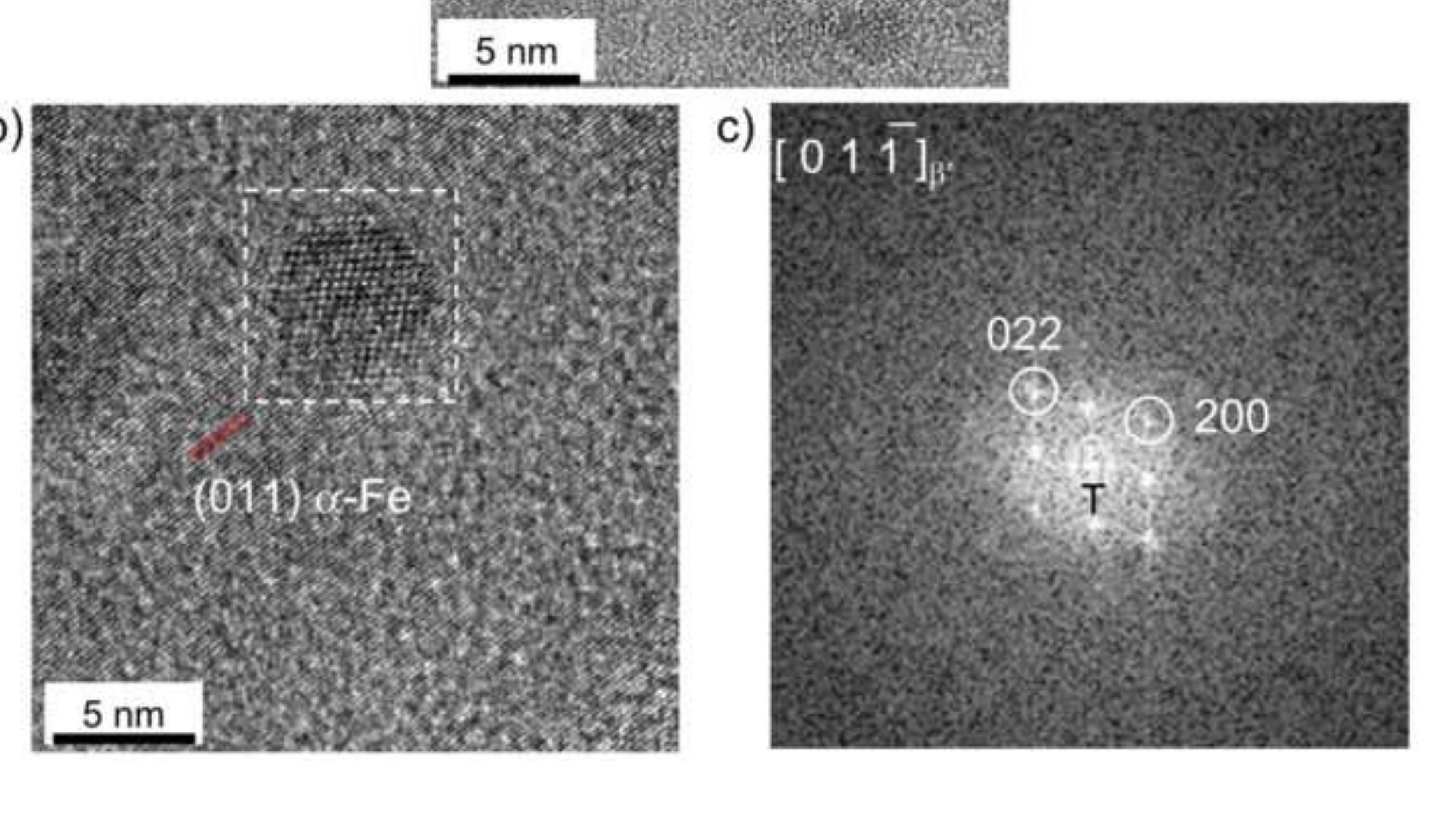

c)
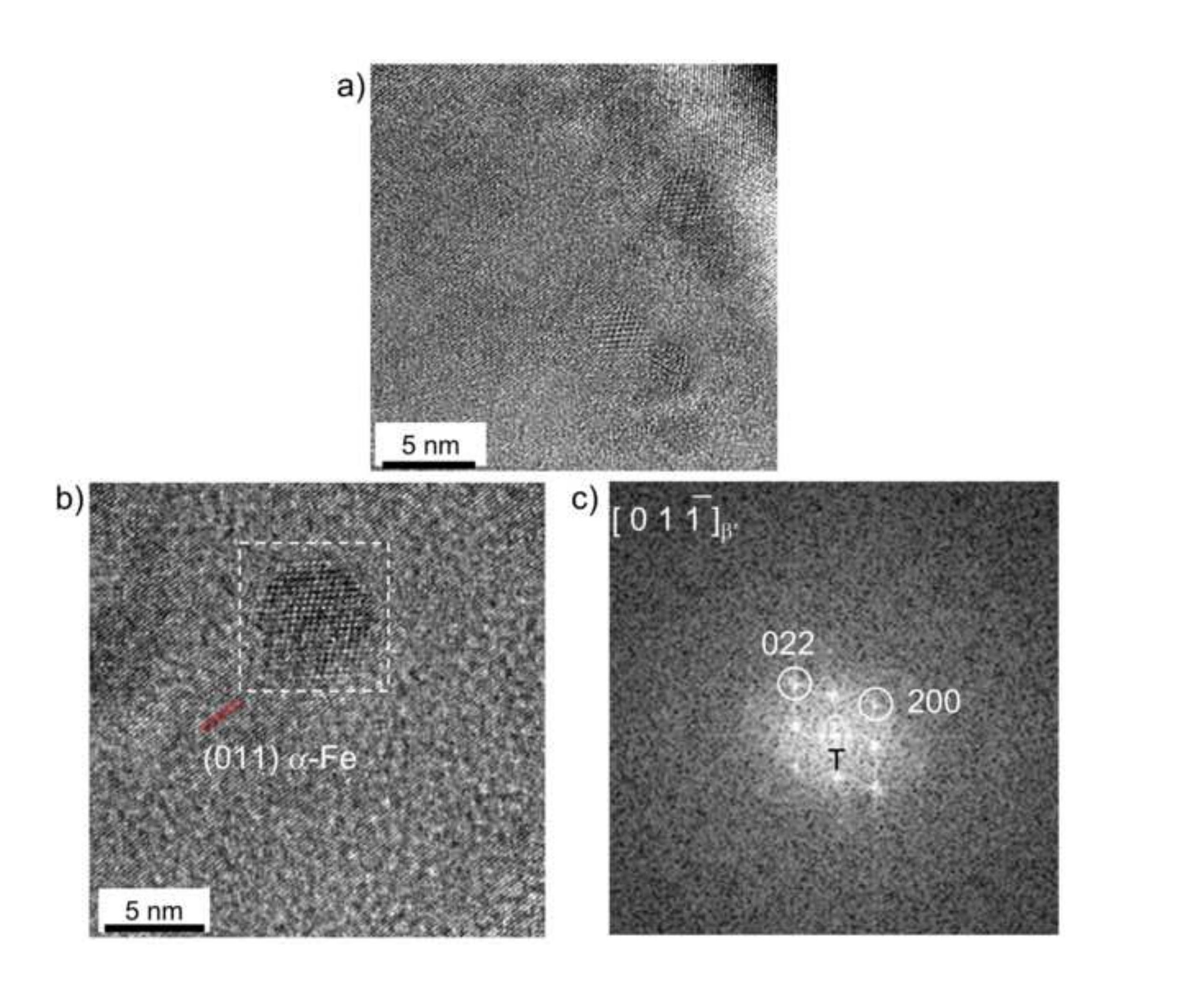

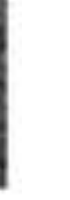

.
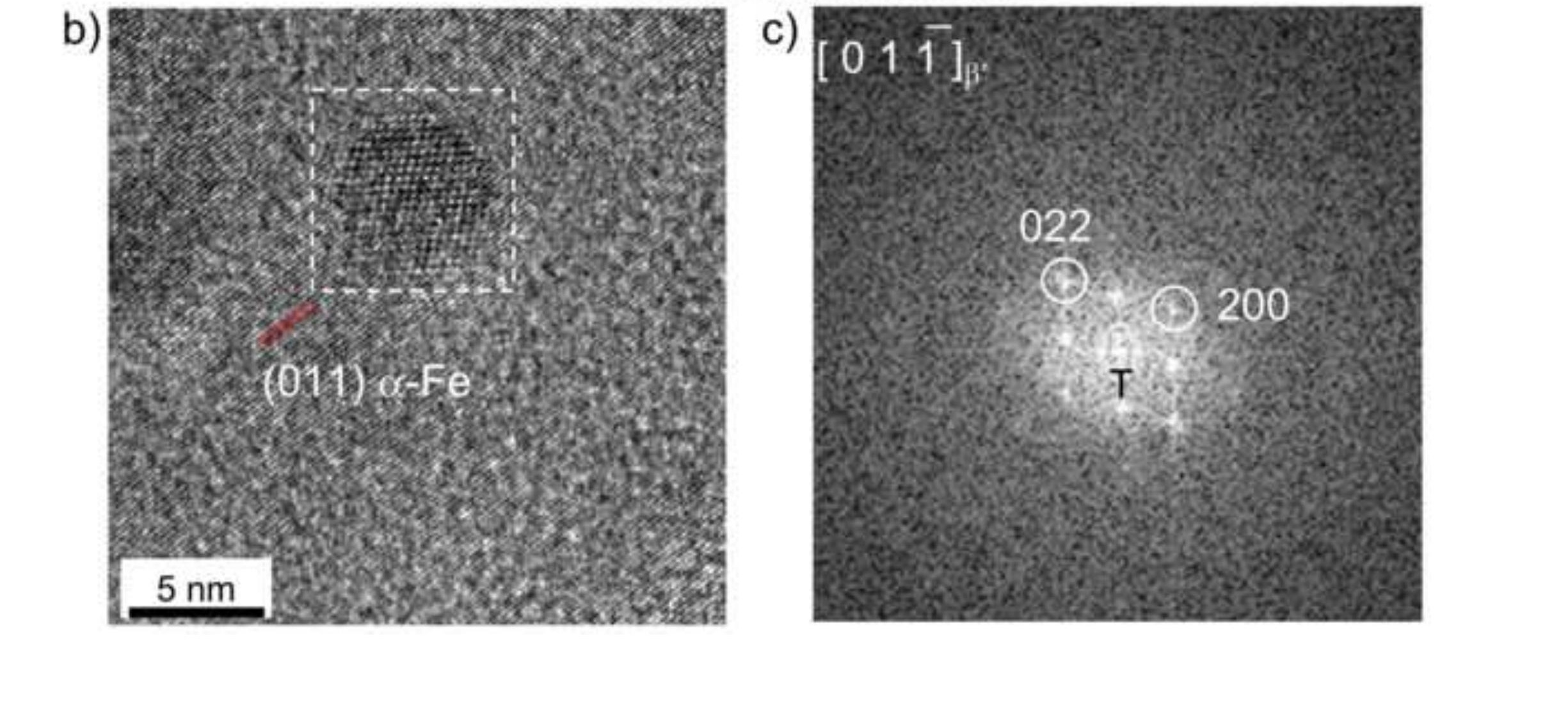

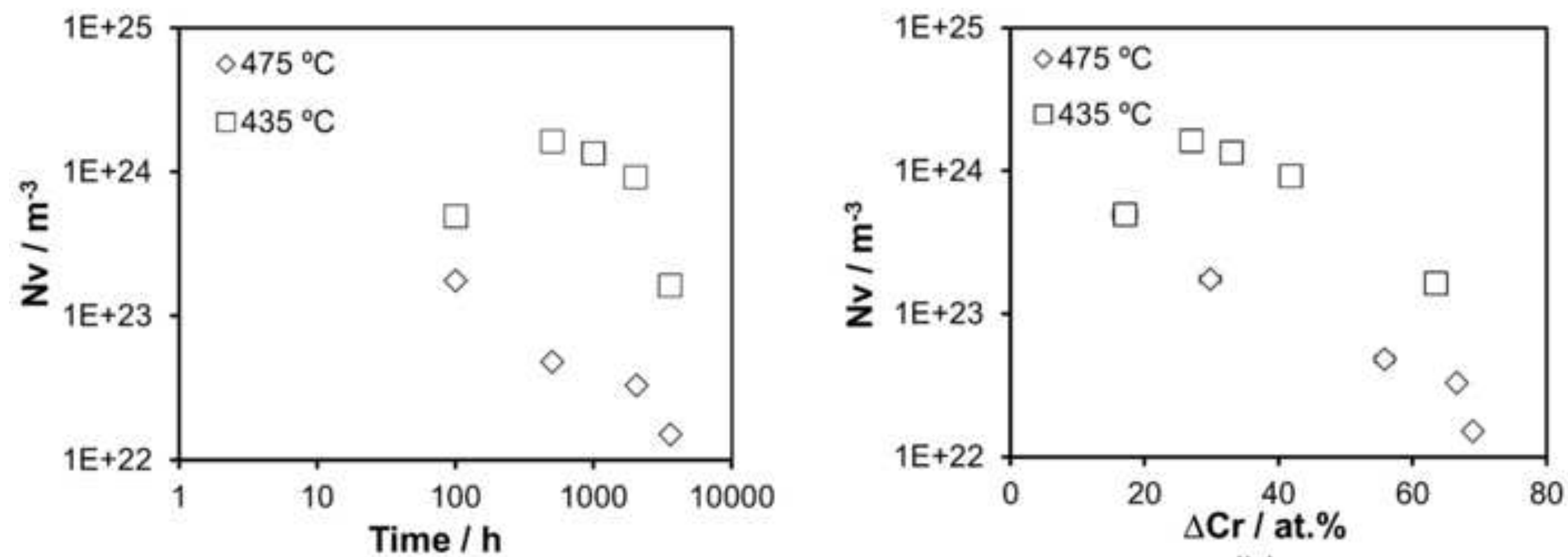

(a)

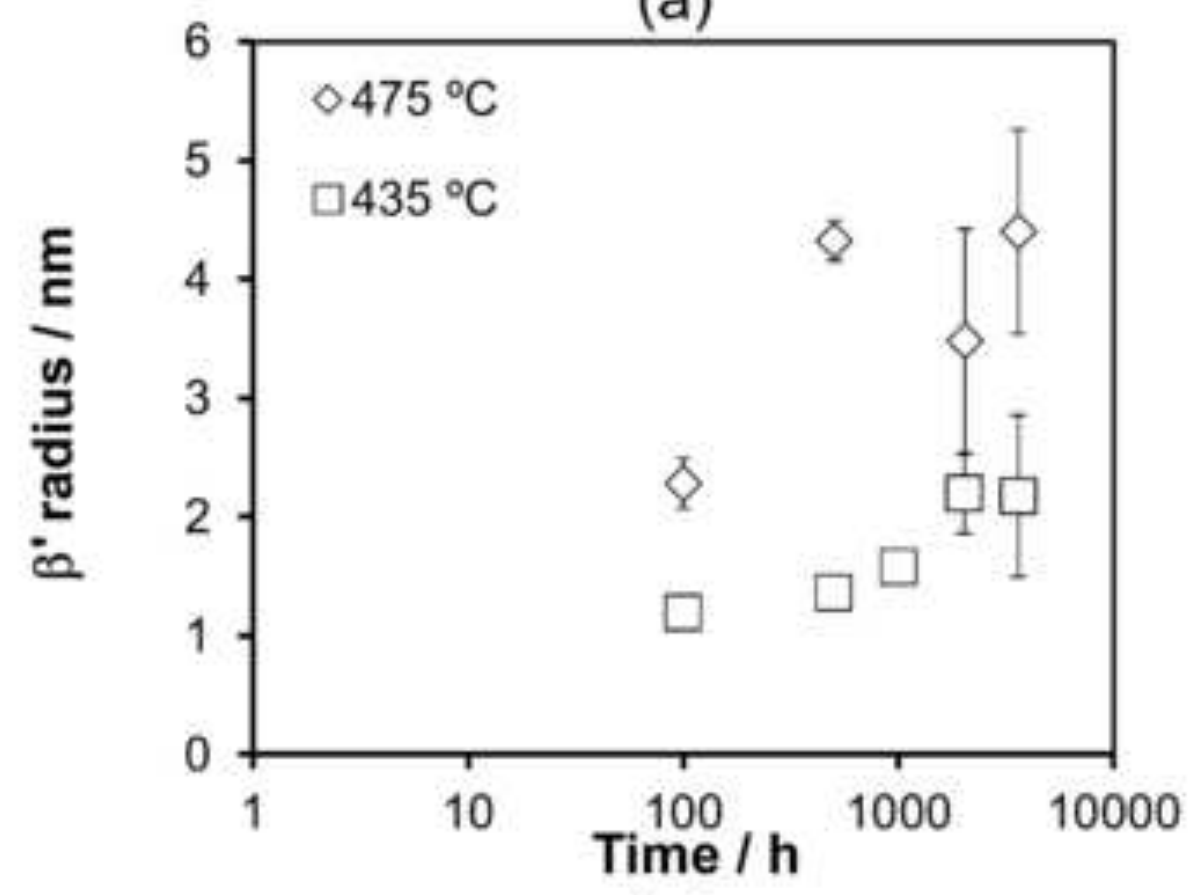

(c)

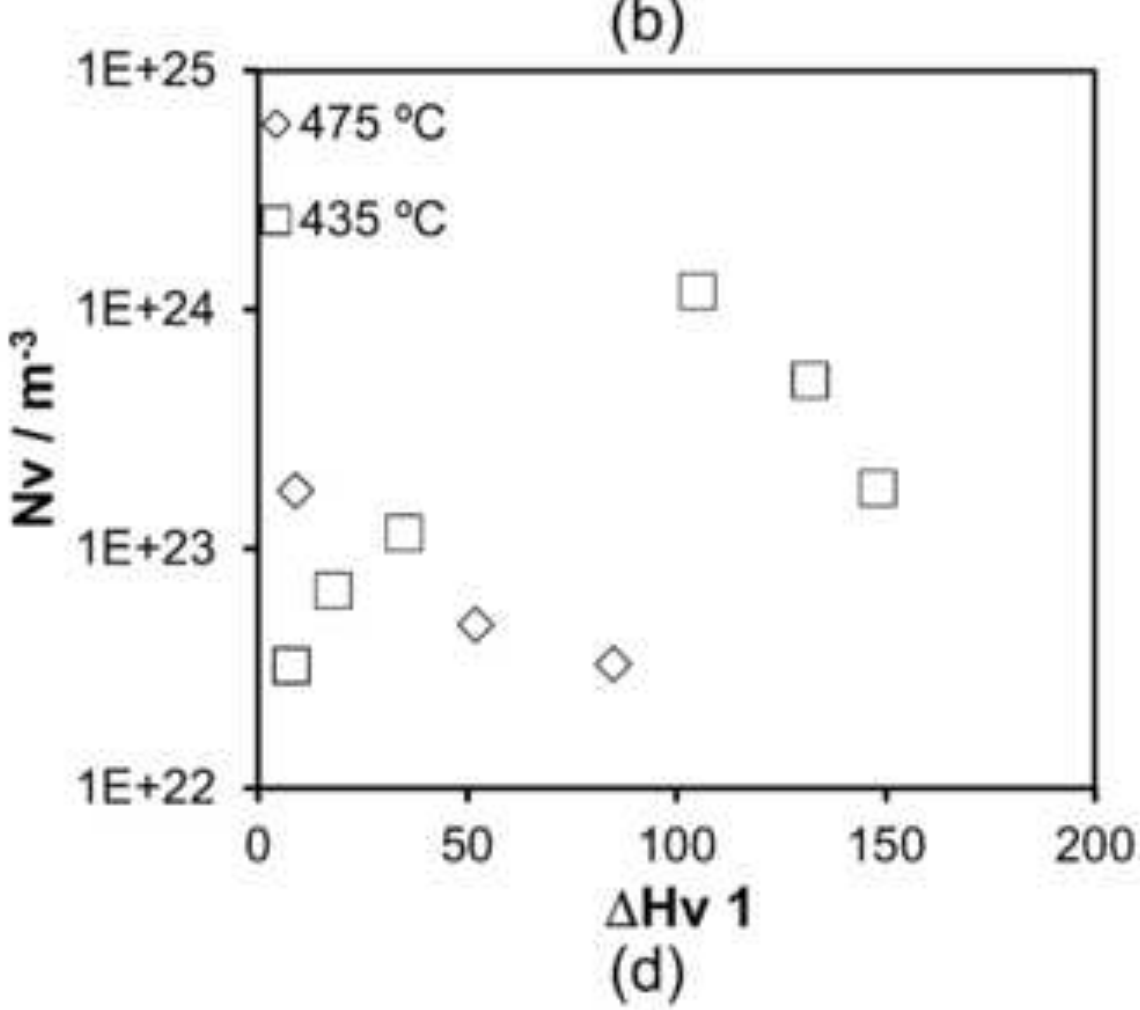


b)

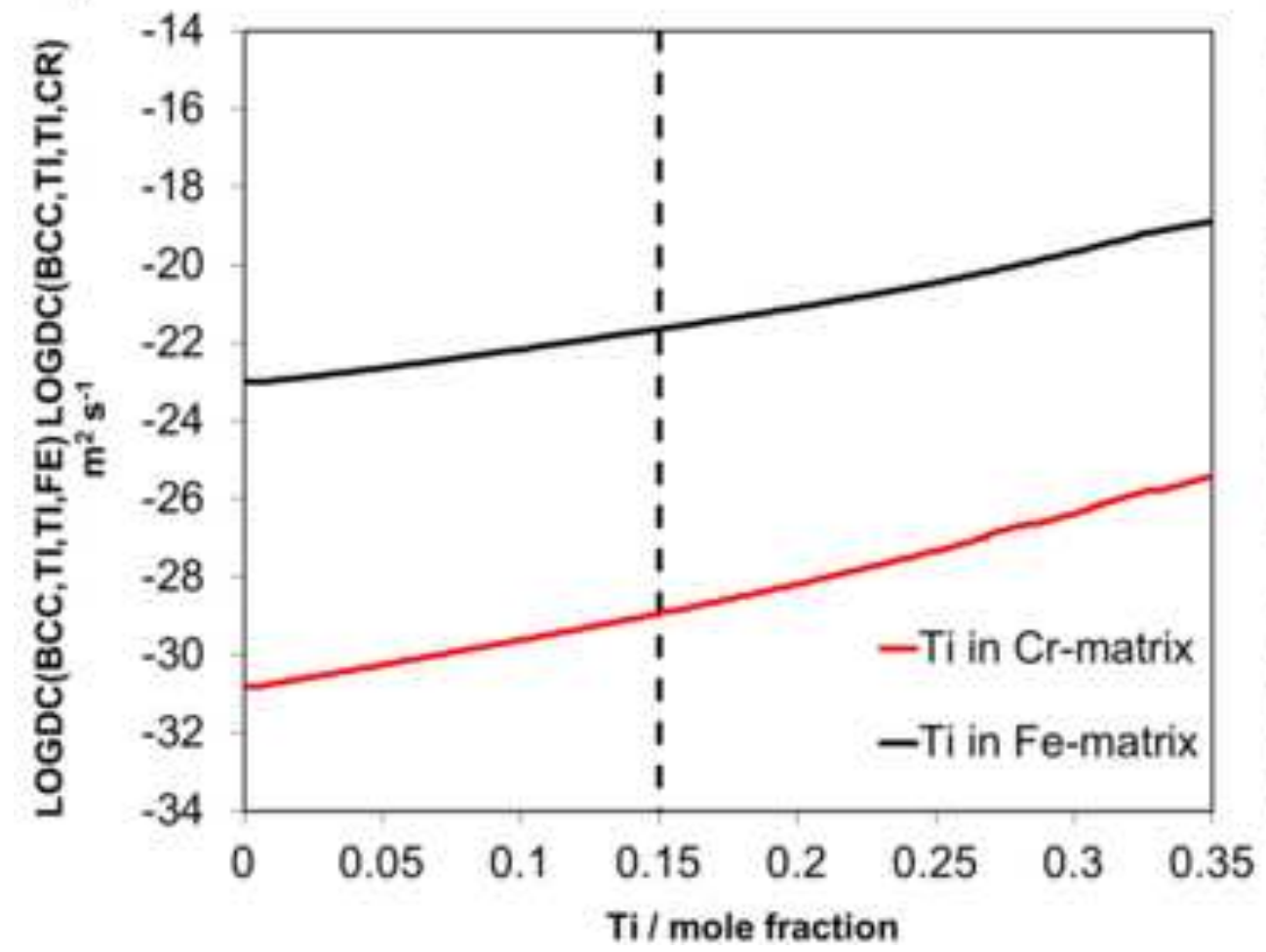

a)

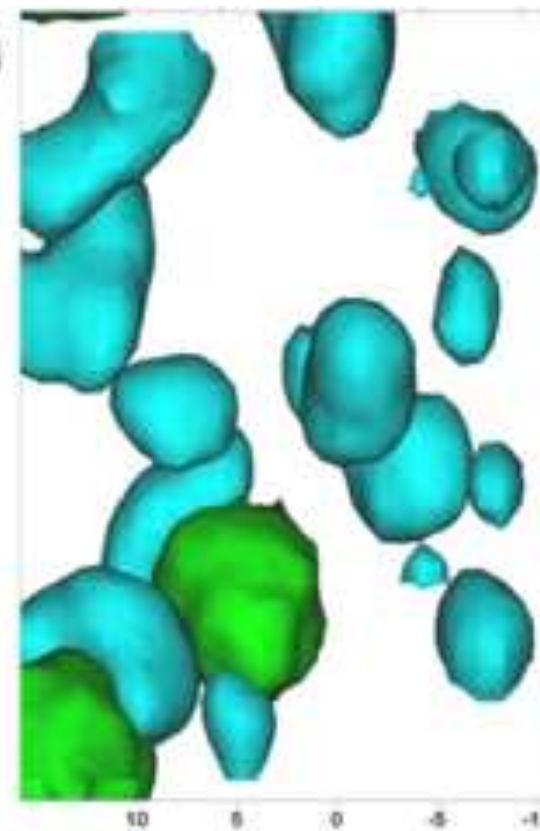

ㅇํำ 옹 |

0

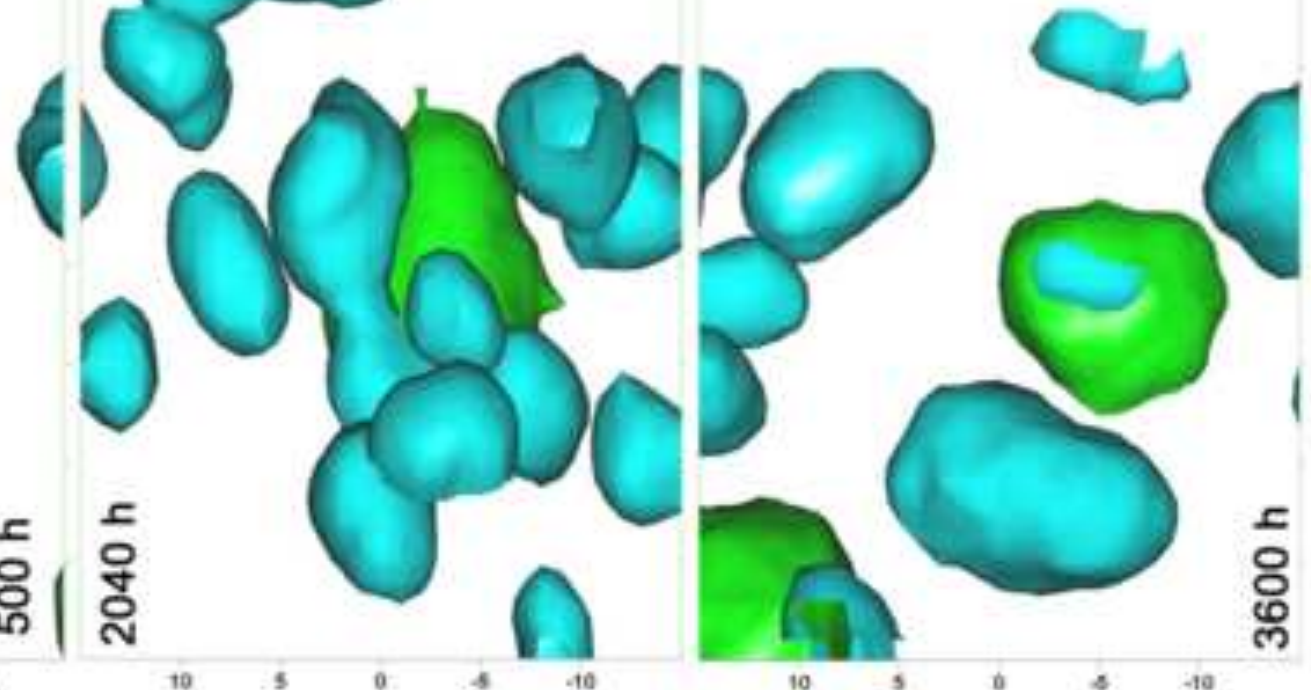

c)

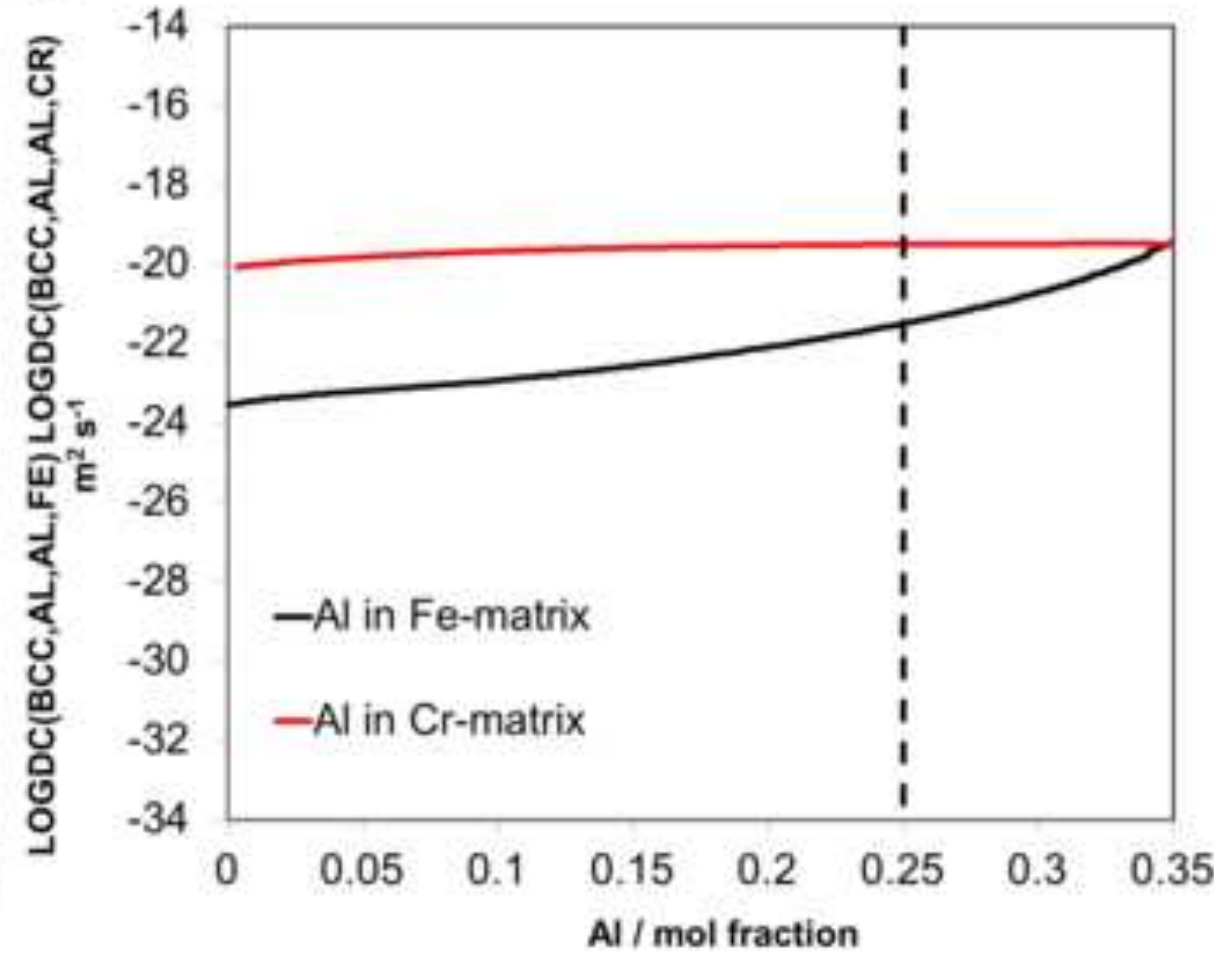




\section{Strengthening by Intermetallic Nanoprecipitation in Fe-Cr-Al-Ti alloy}
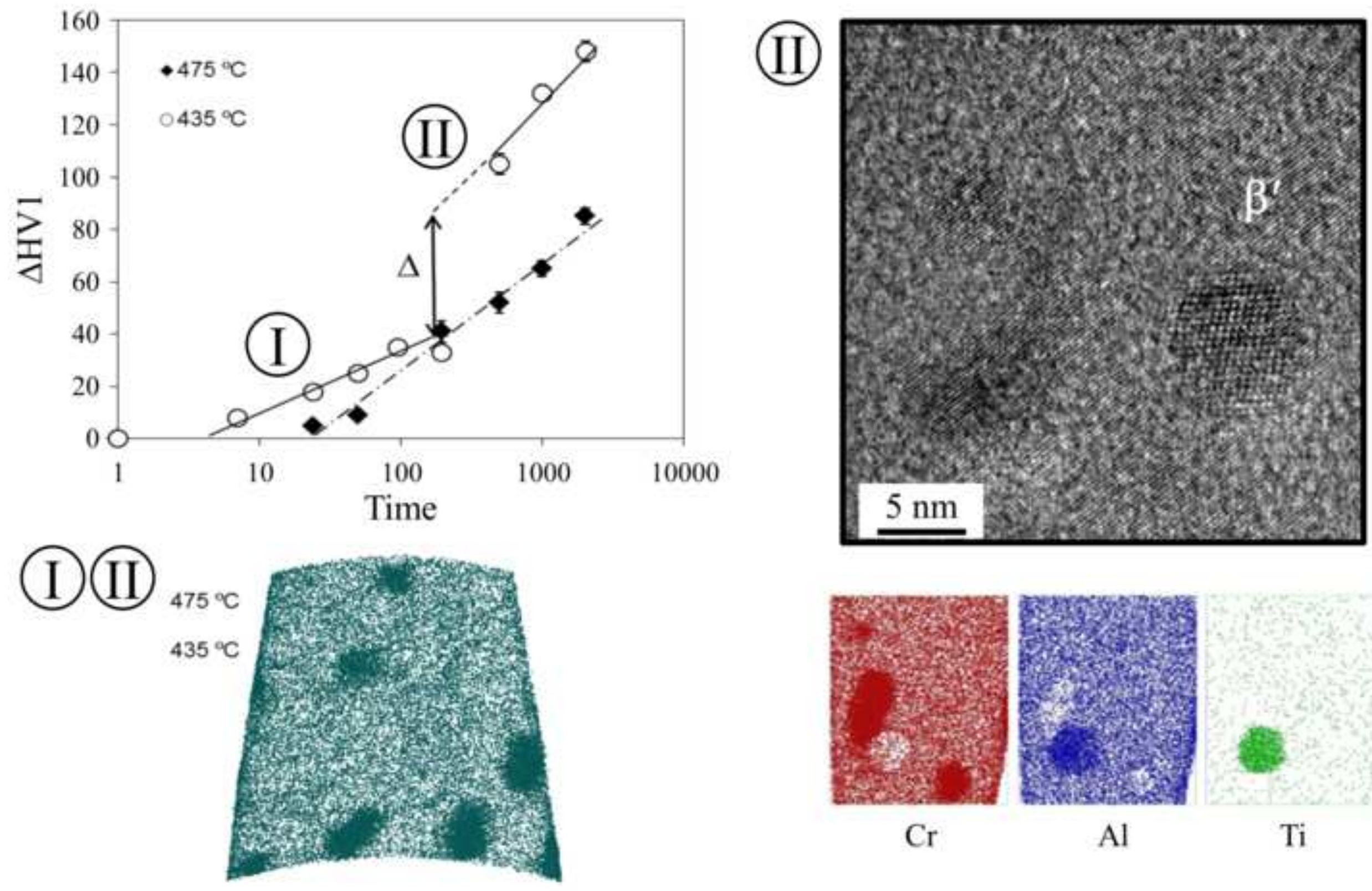

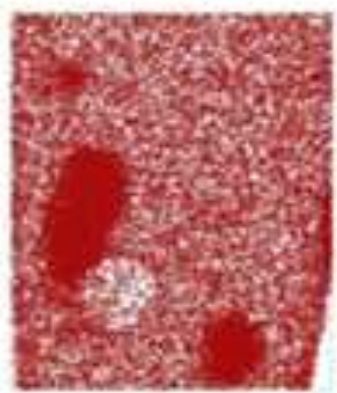

$\mathrm{Cr}$

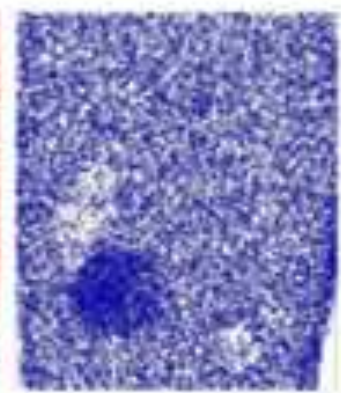

$\mathrm{Al}$

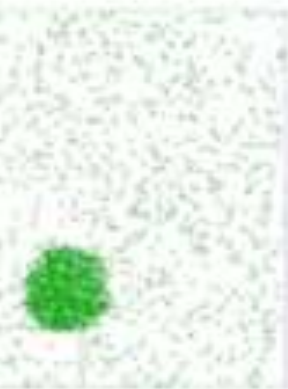

$\mathrm{Ti}$ 